Esta revista forma parte del acervo de la Biblioteca Jurídica Virtual del Instituto de Investigaciones Jurídicas de la UNAM http://www.juridicas.unam.mx/

\title{
MIGRACIÓN, ATENCIÓN A REFUGIADOS Y LIBRE COMERCIO, MÉXICO
}

\author{
Oscar CRUZ BARNEY*
}

\begin{abstract}
SUMARIO: I. Introducción. Las relaciones comerciales México-Estados Unidos de América y la migración. II. Acciones anunciadas por el Poder Ejecutivo estadounidense en materia de comercio exterior y migración relacionadas con México. III. Atención a refugiados y acceso a la justicia. IV. Los mecanismos de defensa y acogida a refugiados. V. La Ley sobre Refugiados, Protección Complementaria y Asilo Político

VI. Conclusión.
\end{abstract}

\section{INTRODUCCIÓN. LAS RELACIONES COMERCIALES MÉXICO-ESTADOS UNIDOS DE AMÉRICA Y LA MIGRACIÓN}

Actualmente hay alrededor de doce millones de mexicanos viviendo fuera de México, de los cuales el $97 \%$ lo hacen en los Estados Unidos de América, constituyendo así el tercer grupo migrante más numeroso en aquel país, después de la India e Irlanda. ${ }^{1}$ Cabe destacar por otra parte que la mayoría de los mexicanos que radica en el resto del mundo son mujeres. ${ }^{2}$

* Abogado. Ex Presidente del Ilustre y Nacional Colegio de Abogados de México. Consejero de la Presidencia de la Union Internationale des Avocats, Senador de la Unión Iberoamericana de Colegios y Agrupaciones de Abogados, Cruz Distinguida de Primera Clase de la Orden de San Raimundo de Peñafort, Cruz de San Ivo del Real e llustre Colegio de Abogados de Zaragoza, Medalla de Honor del llustre Colegio de Abogados de Madrid, Académico Honorario de la Real Academia de Jurisprudencia y Legislación de Madrid. Investigador Nacional Nivel III, Investigador del Instituto de Investigaciones Jurídicas de la UNAM.

1 Rendón, Eunice, "Las comunidades al centro de la política exterior mexicana", en Revista Mexicana de Política Exterior, Núm. 107, mayo-agosto de 2016, pág. 13.

2 Véase http://www.ime.gob.mx/gob/estadisticas/mundo/estadistica_poblacion_2015. html. 
Esta revista forma parte del acervo de la Biblioteca Jurídica Virtual del Instituto de Investigaciones Jurídicas de la UNAM

\section{OSCAR CRUZ BARNEY}

Además de los Estados Unidos de América, los países con el mayor número de mexicanos residiendo en ellos son: Canadá, España, Alemania, Reino Unido, Bolivia, Argentina, Países Bajos, Costa Rica, Chile y Panamá. Suman un total aproximado de 294,781 personas. ${ }^{3}$

Asimismo, los 10 estados de la República Mexicana que presentan la mayor expulsión de migrantes a nivel mundial (sin contar a los Estados Unidos de América) son: Ciudad de México, Chihuahua, Estado de México, Jalisco, Nuevo León, Veracruz, Puebla, Coahuila, Guanajuato y Michoacán. ${ }^{4}$

La Secretaría de Relaciones Exteriores, por medio del Instituto de los Mexicanos en el Exterior, es responsable de mantener al día la base de datos que contiene las matrículas consulares de alta seguridad con el propósito de conocer el estado de origen y residencia, municipio, género, edad promedio, nivel de escolaridad y ocupación de las comunidades mexicanas establecidas en los Estados Unidos. ${ }^{5}$ Hoy en día hay alrededor de 35 millones de personas de origen mexicano que viven en los Estados Unidos, de los cuales uno de cada tres es joven. 6 Una de las tareas del Instituto de los Mexicanos en el Exterior a partir del año 2011 es, además de fortalecer los vínculos con México, la de fomentar la integración de los mexicanos en las comunidades en las que residen y se desenvuelven. ${ }^{7}$

La matrícula consular mexicana de alta seguridad es un documento oficial emitido por el gobierno de México para registrar a sus ciudadanos en el exterior, documento exclusivo para mexicanos, es válido para retornar a México; y no puede ser utilizado para viajar a otros países o para la realización de trámites migratorios. ${ }^{8}$ Cabe destacar que no sustituye al pasaporte.

La población de origen mexicano en los Estados Unidos creció de manera importante entre 2000 y el 2010 conforme al censo de dicho año. Pasó de 20.6 millones en 2000 a 31.8 en $2010 .{ }^{9}$ Los estados de la

\footnotetext{
3 Idem.

4 Idem.

5 La información ha sido compilada y procesada por la Dirección General de Servicios Consulares, la Dirección General de Tecnologías de Información e Innovación, y el Instituto de los Mexicanos en el Exterior de la Secretaría de Relaciones Exteriores.

6 Rendón, Eunice, op. cit., p. 13.

7 Délano Alonso, Alexandra, "¿Un puente hacia la integración? Las políticas mexicanas de vinculación con la diáspora”, en Revista Mexicana de Política Exterior, núm. 107, mayo-agosto de 2016, p. 68.

8 http://www.ime.gob.mx/gob/estadisticas/usa/estadisticas_usa.html

9 Véase Ennis, Sharon R., Merarys Ríos-Vargas, and Nora G. Albert, The Hispanic Population: 2010, 2010 Census Briefs, Issued May 2011. https://www.census.gov/prod/ cen2010/briefs/c2010br-04.pdf
} 
Esta revista forma parte del acervo de la Biblioteca Jurídica Virtual del Instituto de Investigaciones Jurídicas de la UNAM

unión americana con mayor población mexicana son California, Texas, Arizona, Illinois, Colorado, Florida, Washington, Nuevo México, Nevada y Georgia. ${ }^{10}$ Es importante destacar que "Se estima que a partir de 2009 ... el número de mexicanos o personas de origen mexicano que regresa al país es prácticamente igual al número de personas que deciden emigrar hacia la Unión Americana". ${ }^{11}$

En el cuadro de distribución porcentual de los migrantes internacionales por motivo del desplazamiento según categoría migratoria 2006$2010^{12}$, el motivo de la migración para los inmigrantes fue: Trabajo 2.8\%, reunirse con la familia $88.9 \%$, estudio 1.1 , se casó o unió 1.4 , otro motivo 3.9 .

Cabe destacar que al tercer trimestre de 2015, la tasa de emigración se estimó en 36.1 personas y la de inmigración en 18.3 por cada 10 mil habitantes. ${ }^{13}$

\section{ACCIONES ANUNCIADAS POR EL PODER EJECUTIVO ESTADOUNIDENSE EN MATERIA DE COMERCIO EXTERIOR Y MIGRACIÓN RELACIONADAS CON MÉXICO}

Durante la campaña presidencial del recientemente electo Donald Trump en los Estados Unidos de América, ${ }^{14}$ se anunciaron diversas medidas en materia de comercio exterior que habrían de desarrollarse en los primeros 100 días de la nueva administración: 15

1. El retiro del recientemente negociado Acuerdo de Asociación Transpacífica o TPP.

10 Rendón, Eunice, op. cit., p. 15.

11 Ibidem, p. 17.

12 Fuente: INEGI. Estimaciones con base en la Encuesta Nacional de Ocupación y Empleo, 2006-2010. Base de datos. Véase http://www.inegi.org.mx/saladeprensa/boleti nes/2016/especiales/especiales2016_01_10.pdf

13 Véase http://www.inegi.org.mx/saladeprensa/boletines/2016/especiales/especiales 2016_01_10.pdf

14 Una explicación de las razones del impacto en la economía mexicana derivado del resultado electoral estadounidense en Calderón Salazar, Jorge Alfonso, "México ante la propuesta de Trump de renegociar el TLCAN", en El Punto sobre la i, México, año 6, núm. 28, 2017.

15 Véase "Here's what will actually happen if Trump withdraws from NAFTA. It's not pretty." Updated by Zeeshan Aleemzeeshan.aleem@vox.com Nov 16, 2016, 8:30am EST. 
Esta revista forma parte del acervo de la Biblioteca Jurídica Virtual del Instituto de Investigaciones Jurídicas de la UNAM

\section{OSCAR CRUZ BARNEY}

2. Renegociar o en su caso denunciar el Tratado de Libre Comercio de América del Norte (TLCAN). ${ }^{16}$ Si bien la posibilidad de la renegociación ya se había planteado años atrás, ${ }^{17}$ recientemente (31 de marzo de 2017) el negociador en funciones de los Estados Unidos, Stephen Vaughn, hizo llegar al Congreso estadounidense un borrador de las posibles áreas de renegociación del Tratado, dividido en 18 temas generales y 48 objetivos específicos. Entre ellos destaca por su gravedad y ciertamente inaceptabilidad la pretensión de eliminar el mecanismo de solución de controversias del capítulo XIX del TLCAN. 18

3. Imponer barreras arancelarias de $45 \%$ a las importaciones a EUA provenientes de China.

4. Imponer barreras arancelarias de $35 \%$ a las importaciones a EUA de bienes provenientes de empresas estadounidenses que hayan mudado sus plantas de producción a México.

Estas medidas han sido criticadas duramente desde los Estados Unidos por no atender a las acciones que podrían llevarse a cabo para mejorar el funcionamiento del TLCAN y recuperar los mercados perdidos ante la presencia de productos chinos. ${ }^{19}$ Inclusive, durante el Agricultural Outlook 2017, organizado por el USDA (Departamento de Agricultura de los Estados Unidos), hubo diversas voces de inconformidad con el retiro de los Estados Unidos del TPP, al considerar que era francamente benéfico para dicho país.

Asimismo, en materia migratoria se anunciaron tanto deportaciones masivas como la construcción de un muro en la frontera con México, que habría de pagar nuestro país y que ha sido rechazado por el gobierno de México. ${ }^{20}$

16 Véase respecto a una posible renegociación del TLCAN "Cargill c.e.o. advocates smart and inclusive trade, immigration policy", en Milling \& Baking News, USA, Sosland Publishing Co., vol. 95, núm. 16, February 14, 2017, pp. 1 y 10.

17 Véase Gallagher, Kevin P; Dussel Peters, Enrique y Timothy, A. (Coords.), The Future of North American Trade Policy: Lessons from NAFTA, The Frederick S. Pardee Center for the Study of the Longer-Range Future Boston University, 2009.

18 Un análisis del borrador en De Maria y Campos Castelló, Mauricio, "EU expresa lineamientos del nuevo TLCAN; ¿y México qué persigue?", en http://www.elfinanciero.com. mx/opinion/eua-expresa-lineamientos-de-nuevo-tlcan-y-mexico-que-persigue.html

19 Wise, Timothy A., "A Progressive Agenda for Renegotiating NAFTA", en Moyers and Company, November 22, 2016. Véase en http://billmoyers.com/story/getting-the-nafta-weneed/\#.

20 Véase en $h$ ttps://www.theguardian.com/world/2017/feb/22/mexico-trump-immigrationforeign-minister-luis-videgaray. 
Esta revista forma parte del acervo de la Biblioteca Jurídica Virtual del Instituto de Investigaciones Jurídicas de la UNAM

Cabe destacar que la frontera entre ambos países es la frontera terrestre con un mayor número de cruces en el mundo y una de las más largas. La Comisión Internacional de Límites y Aguas se encarga del trazado y determinación de la frontera conforme a los Tratados de 1848, 1853 y 1882. Conforme al Tratado de Límites de 1970, la Comisión llevó a cabo el establecimiento de los límites marítimos en el Golfo de México y en el Océano Pacífico. Actualmente tiene el compromiso de llevar a cabo los trabajos necesarios para asegurar la permanencia y visibilidad de los monumentos y mojoneras internacionales en la frontera terrestre, conforme al acta 244 de la Comisión, y de mantener los ríos Bravo y Colorado como frontera internacional conforme al Tratado de Límites de 1970.21 La frontera mide 3,185 kilómetros desde el Océano Pacífico hasta el Golfo de México. Cuatro estados de Estados Unidos (California, Arizona, Nuevo México y Texas) y seis estados mexicanos (Baja California, Sonora, Chihuahua, Coahuila, Nuevo León y Tamaulipas) tienen territorio a lo largo de la misma. Desde el año 2014, cerca de mil cincuenta kilómetros de la frontera cuentan con una valla fronteriza. Una parte está reforzada con cercas secundarias y terciarias. ${ }^{22}$

No es la primera vez que se legisla alrededor de la idea de construir un muro o valla fronteriza. El 26 de octubre de 2006 se firmó la Secure Fence Act of 2006 por el entonces presidente George W. Bush ${ }^{23}$ que se relaciona con y modifica la Illegal Immigration Reform and Immigrant Responsibility Act of 1996.24

No olvidemos que las decisiones tomadas conforme a dicha ley están sujetas a revisión judicial.

\section{ATENCIÓN A REFUgIADOS Y ACCESO A LA JUSTICIA}

En 2015 la Oficina en Washington para Asuntos Latinoamericanos (WOLA, por sus siglas en inglés) y nueve organizaciones con presencia en México como FUNDAR (Centro de Análisis e Investigación), Casa del Migrante Saltillo, Una Nación Un Mundo A.C., Centro Comunitario de Atención al

21 Véase en http://www.gob.mx/sre/acciones-y-programas/jurisdiccion-de-la-cila-enla-linea-divisoria-internacional-mexico-estados-unidos.

22 Véase en http://www.as-coa.org/articles/explainer-history-and-future-hurdles-usmexico-border-wall?gclid=CNKFiL2qqdMCFU64wAodijQMew.

23 Véase en https://georgewbush-whitehouse.archives.gov/news/releases/2006/10/ images/20061026_p102606kh-0112jpg-515h.html. Su texto en https://www.gpo.gov/fdsys/ pkg/PLAW-109pub/367/html/PLAW-109pub/367.htm.

24 Véase en https://www.uscis.gov/sites/default/files/ocomm/ilink/0-0-0-10948.html. 
Esta revista forma parte del acervo de la Biblioteca Jurídica Virtual del Instituto de Investigaciones Jurídicas de la UNAM

\section{OSCAR CRUZ BARNEY}

Migrante y Necesitado, Centro de Recursos para Migrantes, Hermanos en el Camino e Iniciativa Kino para la Frontera publicaron el Informe de Investigación "un camino incierto. Justicia para delitos y violaciones a los derechos humanos contra personas migrantes y refugiadas en México"25 en el que destacaron los siguientes puntos fundamentales:

El Programa Frontera Sur ha aumentado de manera significativa los operativos, las detenciones y las deportaciones de migrantes.

Entre julio de 2014 y junio de 2015, las detenciones de migrantes subieron el 73 por ciento respecto al mismo periodo para el año anterior.

Entre julio de 2013 y junio de 2014, se detuvieron a 97 mil 245 migrantes, mientras entre julio de 2014 y junio de 2015 se detuvieron a 168 mil 280 migrantes.

Además, existen cifras que indican un aumento en los operativos de revisión migratoria, si bien hacen falta cifras más confiables.

La intensificación de controles ha engendrado un aumento de violaciones a los derechos humanos contra migrantes.

Se han documentado abusos en dichos operativos que se llevan a cabo cada vez más en colaboración con instancias de seguridad. Las casas de migrantes han documentado secuestros, extorsiones, robos y agresiones a lo largo del país.

En este escenario, los esfuerzos del gobierno mexicano por fortalecer sus capacidades para proteger a las personas migrantes han quedado muy por debajo de sus necesidades.

Por ejemplo, el hecho de que "la Comisión Mexicana de Ayuda a Refugiados, solamente tiene 15 oficiales de protección en todo el país para garantizar el acceso a la protección internacional para una población de más de 100 mil personas migrantes detenidas a lo largo de un año, y el presupuesto de aquel órgano no creció en términos reales entre los años 2014 y 2015".

El acceso efectivo a la justicia para las víctimas de delitos y violaciones a los derechos humanos es algo sobre lo cual no existe evidencia, esto a pesar de la creación de nuevas fiscalías especializadas.

Hay una carencia de datos contundentes sobre la procuración de justicia para migrantes en México. Los datos más precisos vienen de la fiscalía especializada en Oaxaca, la cual reporta que, de las 383 denuncias de delitos recibidas en cuatro años, sólo 96 resultaron en una averiguación previa, mientras sólo cuatro resultaron en sentencias para los perpetradores.

25 Véase Knippen, José, Clay Boggs y Maureen Meyer, UN CAMINO INCIERTO. Justicia para delitos y violaciones a los derechos humanos contra personas migrantes y refugiadas en México, Informe de Investigación, Noviembre de 2015. Consultable en https:// www.wola.org/wp-content/uploads/2015/11/Un-camino-incierto_Nov2015.pdf. 
Esta revista forma parte del acervo de la Biblioteca Jurídica Virtual del Instituto de Investigaciones Jurídicas de la UNAM

MIGRACIÓN, ATENCIÓN A REFUGIADOS Y LIBRE COMERCIO MÉXICO

Asimismo, de las mil 617 quejas de violaciones a los derechos humanos contra migrantes recibidas por la Comisión Nacional de los Derechos Humanos del 1 de diciembre de 2012 hasta el 15 de junio de 2015, solamente cuatro resultaron en una recomendación formal a la institución señalada como responsable.

El Programa Frontera Sur se ha enfocado en acciones de control y esto se ve reflejado en el presupuesto del Instituto Nacional de Migración, ya que en 2014 gastó el mayor presupuesto de su historia.

Por su parte, el gobierno de los Estados Unidos ha ofrecido un apoyo político y financiero al gobierno de México para el control migratorio, especialmente después del aumento drástico en las llegadas de niños no acompañados y familias migrantes, la mayoría centroamericanos, a la frontera suroeste de los Estados Unidos.

En el informe se destaca la enorme importancia del trabajo que realizan las casas de migrantes en México en defensa de los derechos humanos de las personas migrantes. La mayoría de los refugios están a cargo o trabajan en coordinación con la Iglesia Católica, "operan con fondos mínimos y poco personal, y representan la primera línea de defensa de migrantes vulnerables. Proporcionan alimentos, refugio temporal, ropa y atención médica, y posibilitan que los migrantes entren en contacto con sus familias. Además, toman testimonio y denuncian delitos y violaciones a los derechos humanos, y en muchos casos el personal de las casas de migrantes ha enfrentado directamente a funcionarios corruptos o indiferentes, incluso miembros de los grupos delictivos organizados". ${ }^{26}$

\section{El Plan Frontera Sur}

El 8 de julio de 2014 se publicó el decreto por el que se crea la Coordinación para la Atención Integral de la Migración en la Frontera Sur mejor conocido como Plan Frontera Sur. En su creación se señala que es de particular relevancia la atención eficiente del fenómeno migratorio en México, por lo que las políticas públicas deben enfocarse a encontrar soluciones sostenibles para facilitar un adecuado flujo de personas al interior del territorio nacional.

La idea es instrumentar una política de Estado en materia migratoria, con un enfoque de atención integral y adecuada gobernanza de las distintas dimensiones de la migración en México, para así contribuir económica y socialmente al proyecto de desarrollo del país.

26 Ibidem, p. 7. 
Esta revista forma parte del acervo de la Biblioteca Jurídica Virtual del Instituto de Investigaciones Jurídicas de la UNAM

\section{OSCAR CRUZ BARNEY}

Se destaca que la meta nacional del Plan Nacional de Desarrollo 2013-2018, denominada "México con Responsabilidad Global", prevé "garantizar en el territorio nacional los derechos de las personas migrantes, solicitantes de asilo, refugiadas y beneficiarias de protección complementaria. Esto incluye diseñar y ejecutar programas de atención especial a grupos vulnerables de migrantes, como niñas, niños y adolescentes, mujeres embarazadas, víctimas de delitos graves, personas con discapacidad y adultos mayores".

Se señala como antecedente que el 30 de abril de 2014, se publicó en el Diario Oficial de la Federación el Programa para la Seguridad Nacional 2014-2018, en el que se establece que será fundamental la consolidación de la Estrategia Integral de Atención a la Frontera Sur, mecanismo impulsado por el Gobierno de la República desde junio de 2013 para fortalecer la presencia de la autoridad del Estado en la zona y coordinar acciones con los países centroamericanos para superar los desafíos comunes a la seguridad y al desarrollo, y avanzar en el establecimiento de una frontera más moderna, eficiente, próspera y segura.

El decreto busca lograr la coordinación necesaria entre la Federación y los estados en la definición de estrategias y proporcionar, dentro de sus respectivas competencias, la atención integral de la migración en la frontera sur.

Entiende por atención integral las acciones que, sujetas al marco jurídico aplicable, corresponde ejecutar de manera coordinada a las dependencias y entidades de la administración pública federal en materia migratoria. Define a la frontera sur como el territorio de los Estados Unidos Mexicanos, que comprende los Estados de Campeche, Chiapas, Quintana Roo y Tabasco.

Por virtud del decreto de creación, se instruye al secretario de Gobernación a fin de que coordine a los servidores públicos del ámbito del Poder Ejecutivo Federal cuando se trate de asuntos en materia migratoria, para dar cumplimiento al propio Decreto. Recordemos que la Secretaría de Gobernación es la encargada de formular y conducir la política demográfica. ${ }^{27}$

Se creó así la Coordinación para la Atención Integral de la Migración en la Frontera Sur, como órgano administrativo desconcentrado de la Secretaría de Gobernación cuyo coordinador será nombrado y removido libremente por el secretario de Gobernación.

27 González Martín, Nuria, Derechos de los inmigrantes, 3a. ed., México, UNAM, Instituto de Investigaciones Jurídicas-Instituto Nacional de Estudios Históricos de las Revoluciones de México- Secretaría de Educación Pública, 2015, p. 40. 
Esta revista forma parte del acervo de la Biblioteca Jurídica Virtual del Instituto de Investigaciones Jurídicas de la UNAM

MIGRACIÓN, ATENCIÓN A REFUGIADOS Y LIBRE COMERCIO MÉXICO

La Coordinación habría de contar con las unidades administrativas y áreas de apoyo necesarias para el ejercicio de sus funciones, de conformidad con las disposiciones aplicables.

Le corresponde al coordinador el ejercicio de las facultades siguientes:

I. Ser el conducto del secretario de Gobernación para la coordinación interinstitucional en materia migratoria.

II. Coordinar y dar seguimiento a la implementación de las distintas políticas públicas en materia migratoria para la atención integral de la migración en la frontera sur.

III. Dar seguimiento a las acciones que se acuerden en el marco de los instrumentos de colaboración y coordinación con las autoridades estatales y municipales correspondientes en materia migratoria.

IV. Recibir en acuerdo a los delegados y demás servidores públicos de las dependencias, entidades e instituciones del Poder Ejecutivo Federal que ejerzan funciones en materia migratoria en la frontera sur, sin perjuicio de la subordinación jerárquica respectiva dentro de aquéllas a las que estén adscritos.

V. Acordar los asuntos en materia migratoria que sean de su competencia con el secretario de Gobernación y, cuando sea necesario, con los titulares de las demás dependencias, entidades e instituciones del ámbito del Poder Ejecutivo Federal para el cumplimiento del objeto del Plan Frontera Sur.

VI. Impulsar el desarrollo, a partir de políticas sociales, económicas y culturales, en coordinación con las autoridades competentes, con el fin de atender la materia migratoria en la frontera sur.

VII. Las previstas en el artículo 70, del Reglamento Interior de la Secretaría de Gobernación, y

VIII. Las demás que le otorgue el secretario de Gobernación para el debido ejercicio de sus funciones.

El Plan Frontera Sur tiene cinco líneas de acción:28

Primera: Paso formal y ordenado. Esta medida permitirá dar certidumbre a la estancia temporal de los migrantes, favorecerá la convivencia entre los habitantes de nuestros países y fortalecerá los intercambios de información entre autoridades. A fin de que su paso por nuestro territorio sea ordenado y seguro, los agentes del Instituto Nacional de Migra-

28 Véase en http://www.gob.mx/presidencia/prensa/pone-en-marcha-el-presidente-enri que-pena-nieto-el-programa-frontera-sur. 
Esta revista forma parte del acervo de la Biblioteca Jurídica Virtual del Instituto de Investigaciones Jurídicas de la UNAM

\section{OSCAR CRUZ BARNEY}

ción y todas las demás autoridades habrán de velar con absoluto respeto a los derechos de los portadores de la Tarjeta de Visitante Regional.

Segunda: Ordenamiento fronterizo y mayor seguridad para los migrantes. La frontera Sur de México debe ser una frontera segura, tanto para los mexicanos como para los migrantes. Con este propósito, se mejorará la infraestructura y equipamientos necesarios para el ordenamiento migratorio. En primer lugar, se asegurará la adecuada operación de los doce cruces fronterizos oficiales, diez con Guatemala y dos con Belice; se transformarán los puntos de revisión aduanales, y ahora habrán de convertirse en Centros de Atención Integral al Tránsito Fronterizo.

Adicionalmente, se reforzarán las líneas móviles de control para asegurar el orden y la legalidad de los flujos de personas y bienes en la frontera.

Tercera: Protección y acción social a favor de los migrantes. Hace un año, el gobierno de la República puso en operación cinco unidades médicas en Chiapas para la atención de migrantes; a la fecha ya se han otorgado más de 16 mil consultas.

Esta línea de acción también contempla mejorar las condiciones en que operan los albergues y estaciones migratorias. Para ello, vamos a reforzar los esquemas de colaboración con las organizaciones de la sociedad civil que atienden y protegen a migrantes.

Cuarta: Corresponsabilidad regional. México ha asumido un papel activo en diversos foros multilaterales en materia migratoria, como la propia Conferencia Nacional sobre Migración.

Quinta: Coordinación interinstitucional. La Coordinación para la Atención Integral de la Migración en la Frontera Sur, adscrita a la Secretaría de Gobernación, tendrá por tarea el establecer la coordinación de los esfuerzos interinstitucionales que se realizan en la frontera sur de nuestro territorio para alcanzar los objetivos señalados, tales como brindar atención y ayuda humanitaria al migrante, y garantizar el estricto respeto a sus derechos humanos.

Esta Coordinación tuvo un presupuesto en 2015 de 102 millones de pesos y 94 empleados. ${ }^{29}$

En el informe de actividades de la Secretaría de Gobernación para julio de 2014 a julio de 2015 se señaló que a un año de haber iniciado sus operaciones, los trabajos de la Coordinación se llevaron a cabo con un enfoque de atención integral, a través de proyectos de desarrollo social y económico, promoviendo una cultura de legalidad y respeto a los derechos humanos.

29 http://www.jornada.unam.mx/ultimas/2015/08/05/desaparecera-oficina-para-laatencion-de-migrantes-282.html. 
Esta revista forma parte del acervo de la Biblioteca Jurídica Virtual del Instituto de Investigaciones Jurídicas de la UNAM

MIGRACIÓN, ATENCIÓN A REFUGIADOS Y LIBRE COMERCIO MÉXICO

En el informe se subraya que las acciones realizadas en los estados de la frontera sur (Campeche, Chiapas, Quintana Roo y Tabasco), particularmente en los 23 municipios fronterizos, están alineadas con la meta "México con Responsabilidad Global", del Plan Nacional de Desarrollo 2013-2018.

Durante este año de actividades, la Coordinación trabajó en dos rubros:

1. En la colaboración interinstitucional para intercambiar información y diseñar políticas públicas en materia migratoria en la región, y

2. El seguimiento de la aplicación de políticas sociales, económicas y culturales que permitan impulsar el desarrollo de la zona.

En la primera etapa del trabajo de la Coordinación para la Atención Integral de la Migración en la Frontera Sur, que comprendió de julio a diciembre de 2014 , se realizaron cursos y talleres de capacitación para sus integrantes, a fin de promocionar la política migratoria del gobierno de la República y conocer las condiciones socio demográficas de la región.

Para estos propósitos, se trabajó conjuntamente con la Subsecretaría de Población, Migración y Asuntos Religiosos de la Secretaría de Gobernación; con la Subsecretaría para América Latina y El Caribe de la Secretaría de Relaciones Exteriores, así como con la Subsecretaría de Desarrollo Urbano y Vivienda; y la Dirección General de Desarrollo Regional de la Secretaría de Desarrollo Agrario, Territorial y Urbano.

Además, se informa que en los últimos tres años se registraron en esta frontera un promedio de 11.1 millones de entradas de personas documentadas y se estiman aproximadamente 250 mil irregulares.

Destaca que durante el primer bimestre de 2015, se han alojado en las estaciones migratorias del sureste mexicano 1,052 menores migrantes acompañados, lo que representa el $55 \%$ del total nacional $(1,910)$; mientras que en ese mismo periodo se registraron 1,316 menores no acompañados, lo que representa el $57 \%$ del total nacional $(2,286)$.

Cabe señalar que para efecto del control de ingreso a territorio mexicano, el Instituto Nacional de Migración (INM) cuenta con 11 puntos de cruces formales de control terrestre y se explica que existen aproximadamente 704 cruces informales.

Por ello, en el marco de las acciones de la Coordinación y con el fin de mantener el control de ingreso a nuestro país, el INM expidió de agosto a diciembre de 2014; 59,988 tarjetas de Visitante Regional y 6,137 de Visitante Trabajador Fronterizo, mientras que en el primer cuatrimestre de 2015, se emitieron 42,157 de Visitante Regional y 6,671 de 
Esta revista forma parte del acervo de la Biblioteca Jurídica Virtual del Instituto de Investigaciones Jurídicas de la UNAM

\section{OSCAR CRUZ BARNEY}

Trabajador Fronterizo. El trámite de las tarjetas se llevó a cabo en cinco módulos itinerantes y en las oficinas ubicadas en siete puntos de internación regular y se otorgan a ciudadanos de Guatemala y Belice.

Otra de las tareas de la estrategia integral de coordinación de la frontera sur, fue la puesta en marcha de operativos para brindar seguridad a los migrantes que utilizan el Ferrocarril del Istmo de Tehuantepec con destino a Estados Unidos. En ese sentido, se pusieron en marcha acciones para combatir los delitos cometidos en contra de migrantes.

Participaron las Secretarías de la Defensa Nacional y de Marina, la Procuraduría General de la República, el Instituto Nacional de Migración, así como la Policía Federal, el gobierno del estado de Chiapas y los representantes del Ferrocarril del Istmo de Tehuantepec.

Se destaca en el informe la creación de tres Fiscalías Especializadas en Delitos Cometidos en contra de Migrantes en los estados de Campeche, Quintana Roo y Tabasco para procurar los derechos humanos de los migrantes y garantizar el acceso a la justicia de las personas en tránsito por nuestro país en caso de ser víctimas de algún delito.

Finalmente, la Coordinación informó de la construcción y puesta en operación de los Centros de Atención Integral de Tránsito Fronterizo en La Trinitaria-Comitán, en Huixtla y en Playas de Catazajá, en Chiapas; agregó que construirán uno en Palenque, Chiapas y otro en Frontera, Tabasco. ción. ${ }^{30}$

Sin embargo, desapareció como tal apenas a un año de su crea-

\section{LOS MECANISMOS DE DEFENSA Y ACOGIDA A REFUGIADOS}

En 2013 la Comisión Interamericana de Derechos Humanos en su estudio Derechos humanos de los migrantes y otras personas en el contexto de la movilidad humana en México, emitió diversas recomendaciones al Estado Mexicano en materia de refugiados, ${ }^{31}$ entre las que destacan:

1. Implementar una política pública específicamente dirigida a prevenir, proteger y sancionar los delitos y violaciones de los dere-

30 Véase $h$ ttp://eleconomista.com.mx/sociedad/2015/08/06/desaparecen-coordinaciontemas-migrantes.

31 Antecedentes para el régimen sobre asilo y protección de refugiados en Latinoamérica en Asilo y protección internacional de refugiados en América Latina, México, Instituto de Investigaciones Jurídicas, UNAM, 1982. Interesante el texto de Guerra Iñiguez, Daniel, El derecho de asilo en Venezuela, Caracas, Universidad Central de Venezuela, Facultad de Ciencias Económicas y Sociales, 1973. 
Esta revista forma parte del acervo de la Biblioteca Jurídica Virtual del Instituto de Investigaciones Jurídicas de la UNAM

chos humanos de las que son víctimas los migrantes y otras personas en el contexto de la movilidad humana, así como los que se cometan en contra de los defensores de derechos humanos que trabajan a favor de estas personas en México.

2. Adoptar medidas tendientes a facilitar que las personas puedan ingresar y transitar por su territorio a través de canales regulares y no tener que recurrir a vías clandestinas, lo que contribuiría a garantizar el acceso a la justicia de los migrantes, dicha medida facilitaría que los migrantes tuviesen una mayor disposición a denunciar los delitos o violaciones a sus derechos humanos.

3. Incrementar la seguridad en las zonas de alto riesgo para las personas migrantes, así como en los medios de transporte y a lo largo de las rutas utilizadas por ellos. El Estado también debe proveer de centros de atención al migrante a lo largo de las rutas migratorias, para asegurar el respeto a sus derechos humanos.

4. Implementar por parte del INM un protocolo para la identificación preliminar de migrantes en situación de vulnerabilidad.

5. Adelantar eficazmente los procesos penales en curso, así como los que se llegasen a abrir, para identificar, procesar y, en su caso, sancionar a los responsables materiales e intelectuales de delitos y violaciones a los derechos humanos de migrantes $u$ otras personas en el contexto de la movilidad humana, asó como defensores de derechos humanos que trabajan en favor de estas personas. En el marco de estos procesos se debe proveer regularmente de información a los familiares de las víctimas sobre los avances en la investigación y darles pleno acceso a los expedientes, y realizarse por funcionarios altamente capacitados en casos similares y, en atención a víctimas de discriminación y violencia en contra de migrantes.

6. Crear una instancia especializada a nivel federal que se encargue de la investigación penal de los delitos y violaciones a sus derechos humanos en contra de migrantes, tal como podría ser una Fiscalía Especial para los Delitos de Violencia contra los Migrantes. A su vez, esta instancia también debe brindar atención integral a las víctimas y sus familiares. Una instancia de este tipo permitiría a los migrantes y sus familiares, entre otros, saber a dónde acudir, focalizar el fenómeno para su atención e investigación, colaborar en la búsqueda de migrantes desaparecidos y en la identificación de cadáveres y restos no identificados que pudiesen ser de migrantes, generar estadísticas confiables y permitiría un monitoreo de los resultados por parte de la sociedad civil. Lo 
Esta revista forma parte del acervo de la Biblioteca Jurídica Virtual del Instituto de Investigaciones Jurídicas de la UNAM

anterior contribuiría en la construcción de políticas públicas dirigidas a prevenir y combatir la violencia y discriminación contra los migrantes. Deberá asegurarse que esta instancia cuente con los recursos humanos y materiales necesarios para desempeñar sus funciones de manera adecuada, independiente e imparcial, y que las personas que participen en la investigación cuenten con las debidas garantías de seguridad.

7. Considerando la información sobre la existencia de numerosos casos de privación de la libertad de migrantes en los que habrían estado vinculados agentes estatales, se debe considerar dentro de las líneas de investigación investigar estos hechos como desaparición forzada.

8. Aprobar una Ley General sobre las Desapariciones Forzadas y garantizar que el delito de desaparición forzada sea incluido en los códigos penales de todas las entidades federativas.

9. Fortalecer los mecanismos tendientes a combatir la corrupción y a promover la rendición de cuentas por funcionarios estatales.

10. Implementar mecanismos de búsqueda de migrantes desaparecidos, no localizados, secuestrados o bajo cualquier forma de privación de la libertad. Estos mecanismos deben estar coordinados entre todas las entidades federativas, la federación y con los países de origen en Centroamérica y los países de destino, principalmente Estados Unidos.

11. Desarrollar mecanismos de investigación efectivos y coordinados regionalmente que permitan a los migrantes agraviados y a sus familiares, independientemente de su situación migratoria y de donde se encuentren, tener un acceso efectivo a la justicia.

12. Fortalecer las instancias federales y estatales de atención a víctimas de delitos y violaciones a sus derechos humanos, y garantizar la accesibilidad y disponibilidad de servicios a personas migrantes que han sido víctimas de delitos o violaciones a sus derechos humanos y sus familiares.

13. Intensificar sus esfuerzos con las autoridades de Estados Unidos de América de forma que las deportaciones de nacionales mexicanos se lleven a cabo en lugares y horarios en los que no se ponga en riesgo los derechos a la vida, la integridad y la libertad personal.

En materia de migrantes desaparecidos, no localizados y restos no identificados se recomendó:

1. En casos de hallazgos de restos y/o cadáveres, que por sus particularidades señalen que podrían ser de migrantes, se preserven 
Esta revista forma parte del acervo de la Biblioteca Jurídica Virtual del Instituto de Investigaciones Jurídicas de la UNAM

los restos no identificados. Se recomienda evitar que los restos que aún permanecen en el Servicio Médico Forense (SEMEFO) sean cremados o enviados a fosas comunes y proteger de cualquier inhumación los restos que ya hayan sido enviados a fosas comunes.

2. Implementar un mecanismo nacional que facilite el intercambio de información forense sobre restos no identificados de personas mexicanas y centroamericanas desaparecidas en México con los bancos forenses de migrantes desaparecidos que se han desarrollado en la región, tales como los de El Salvador, Guatemala, Honduras, el del estado de Chiapas, así como otros que puedan surgir. Este mecanismo nacional debe integrarse en un mecanismo regional similar que extiende el cruce de información forense entre los países de Centroamérica y Norteamérica. Ambos mecanismos deben contar con la participación de organismos de la sociedad civil en su dirección.

En materia de trata de personas:

1. Elaborar una evaluación sobre el perfil de los perpetradores y de las víctimas de trata de personas en México.

2. Establecer albergues a cargo del Estado especializados en brindar asistencia a mujeres y hombres que han sido víctimas de trata de personas.

3. Desarrollar acciones para reducir la demanda de trabajos forzados y para castigar a los empleadores e intermediarios de migrantes para explotación laboral.

En materia de derechos de las mujeres:

1. Elaborar políticas públicas para combatir la discriminación, la explotación y el abuso del cual son víctimas las mujeres migrantes. Estas políticas deben desarrollarse desde una perspectiva de género.

2. Llevar a cabo una evaluación sobre las prioridades y necesidades de las mujeres migrantes, refugiadas o desplazadas, el cual preste particular atención a la situación de las niñas que se encuentran en alguno de estos grupos.

En materia de desplazamiento forzado:

1. Llevar a cabo un estudio para "caracterizar" el desplazamiento interno en México y, consecuentemente, adoptar medidas tendientes a prestar una respuesta conforme a los estándares interna- 
Esta revista forma parte del acervo de la Biblioteca Jurídica Virtual del Instituto de Investigaciones Jurídicas de la UNAM

\section{OSCAR CRUZ BARNEY}

cionales en la materia, en particular los Principios Rectores del Desplazamiento Interno.

2. Adoptar legislación específica a nivel federal y estatal para abordar el desplazamiento interno, de conformidad con los Principios Rectores del Desplazamiento Interno.

3. Crear a nivel federal una institución o punto focal a cargo de la protección de las personas contra el desplazamiento forzado, así como de asistencia durante su traslado y el retorno o el reasentamiento, y la reintegración.

Cabe destacar que en el informe se recomienda que por su parte, los Estados de la región deben:

1. Si bien la Comisión reconoce que México tiene la responsabilidad primaria de garantizar el respeto y garantía de los derechos humanos de las personas que conforman los flujos migratorios mixtos que ingresan y atraviesan su territorio, la Comisión reconoce que para que las acciones que México realiza para dicha acción de garantía alcance también es imperativa la corresponsabilidad por parte de países de origen, y destino en el abordaje de los factores de expulsión y atracción de migrantes.

2. Los países de destino de migrantes, tales como Estados Unidos y Canadá, deben adoptar medidas tendientes a facilitar que las personas puedan migrar a través de canales regulares.

3. Los países de origen de migrantes, en particular El Salvador, Guatemala y Honduras, pero también otros Estados de la región, deben adoptar las políticas y medidas que sean necesarias para abordar los factores de expulsión que fuerzan a las personas a migrar de sus países. En este rubro es particularmente importante el abordaje de problemáticas como la desigualdad, la pobreza y la violencia.

4. Desarrollar instrumentos y mecanismos regionales para combatir las actividades ilegales de las organizaciones delictivas transnacionales involucradas en el secuestro de migrantes, la trata de personas y el tráfico ilícito de migrantes.

En materia de detención migratoria y debido proceso, la Comisión recomendó a México:

1. En materia de acciones de revisión, verificación y control migratorio se deben adoptar las medidas necesarias para garantizar que no se lleven a cabo acciones como los interrogatorios, las detenciones y los cacheos basados de facto exclusivamente en 
Esta revista forma parte del acervo de la Biblioteca Jurídica Virtual del Instituto de Investigaciones Jurídicas de la UNAM

el aspecto físico de la persona, su color, sus rasgos faciales, su pertenencia a un grupo racial o étnico o cualquier otra categoría que pueda hacerle particularmente sospechoso.

2. En materia de detención migratoria, establecer por vía legal una presunción general de la libertad personal de migrantes, solicitantes de asilo, refugiados y otras personas en necesidad de protección internacional. La detención de migrantes en situación migratoria irregular, solicitantes de asilo, refugiados, apátridas y otras personas en necesidad de protección internacional es una medida intrínsecamente indeseable, por lo cual debe ser una medida excepcional, aplicada como medida de última recurso y por el menor tiempo posible.

3. Implementar un mecanismo de evaluación de riesgos que parta de una presunción a favor de la libertad y establezca criterios claros para determinar los casos excepcionales en los que la detención migratoria es procedente.

4. Establecer y ampliar por vía legal las medidas alternativas a la detención migratoria ya existentes; la aplicación de estas medidas debe funcionar como la regla en casos de migrantes en situación irregular, solicitantes de asilo, refugiados y otras personas en necesidad de protección internacional que se encuentren en el marco de un procedimiento tendiente a determinar su situación migratoria o en un procedimiento para la determinación de la condición de refugiado. En este orden de ideas, para que las medidas alternativas a la detención sean efectivas es necesario fortalecer las condiciones de acogida y el apoyo en la comunidad.

5. Adoptar medidas legislativas que garanticen que las personas en una situación de vulnerabilidad, tales como los refugiados, las víctimas de trata de personas, las víctimas de delitos, los niños, niñas y adolescentes (NNA), los sobrevivientes de tortura y traumas, las mujeres embarazadas, las madres lactantes, los adultos mayores, las personas con discapacidad o quienes tienen necesidades de salud física o mental, no sean puestos bajo detención migratoria.

6. Adoptar medidas legislativas que garanticen que los NNA -independientemente de que estén acompañados o no acompañados-no sean puestos bajo detención migratoria. El interés superior de los NNA debe ser protegido de conformidad con el artículo 19 de la Convención Americana y las obligaciones emanadas de la Convención sobre los Derechos del Niño. Los NNA no deben ser separados de sus familiares o tutores, y si no están acom- 
Esta revista forma parte del acervo de la Biblioteca Jurídica Virtual del Instituto de Investigaciones Jurídicas de la UNAM

\section{OSCAR CRUZ BARNEY}

pañados, deben realizarse arreglos para su cuidado a cargo de un organismo capacitado y especializado para llevar a cabo tal función.

7. Garantizar que el procedimiento para determinar el interés superior de los NNA sea dirigido por un organismo técnico especializado, independiente de la autoridad migratoria, que realice una evaluación que considere las características particulares de cada caso.

En materia de garantías procesales y protección judicial:

1. Garantizar que la decisión sobre la detención migratoria se ejerza de acuerdo con las obligaciones convencionales, constitucionales y legales del Estado mexicano, que no sea arbitraria y que esté sujeta a una revisión judicial periódica. Las personas detenidas deben tener el derecho a recurrir la legalidad de su detención, la cual debe incluir el derecho de asistencia legal y el poder de un juez o tribunal de ordenar la liberación del detenido, la cual debe ser cumplida oportunamente por las autoridades del Instituto Nacional de Migración (INM).

2. Informar a las personas bajo detención migratoria sobre su derecho a solicitar asistencia consular, y que existan los medios para que puedan comunicarse con sus consulados en caso de que lo requieran.

3. Adoptar las medidas necesarias para que la duración de la detención migratoria sea por el menor tiempo posible y con límites definidos sobre la misma, los cuales deben ser cumplidos estrictamente.

4. Realizar las modificaciones legales que sean necesarias para garantizar que ningún migrante, solicitante de asilo, refugiado u otras personas en necesidad de protección internacional sea sometida a detención migratoria indefinida.

5. Adoptar todas las medidas necesarias para garantizar, no solo por vía legal, sino particularmente en la práctica de las autoridades del INM, que desde el momento en que se inicie un procedimiento administrativo migratorio, así como cuando se decida detener a un migrante, se salvaguarden las garantías del debido proceso reconocidas en la Convención Americana, la Constitución mexicana, la Ley de Migración, así como en otras normas aplicables. Esto incluye el derecho de estas personas a contar con las condiciones necesarias para que pueden defenderse en el marco de los procedimientos migratorios que se les adelantan y cuestionar 
Esta revista forma parte del acervo de la Biblioteca Jurídica Virtual del Instituto de Investigaciones Jurídicas de la UNAM

las decisiones que les afecten. En este sentido, se debe garantizar que en todas las fases de sus procedimientos migratorios las personas involucradas cuentan con asistencia jurídica y traductores, se les informa sobre sus derechos, mecanismos e instancias para recurrir dichas decisiones, y que estas se encuentren debidamente fundamentadas.

6. Garantizar que la autoridad encargada de llevar a cabo la revisión cuente con la independencia y autonomía suficiente, para la toma de decisiones, con acceso a conocimientos especializados y medios para tomar decisiones fundamentadas. A su vez, debe garantizarse que los solicitantes de la condición de refugiados tengan acceso efectivo a protección judicial.

7. Garantizar que los migrantes solo sean expulsados por decisión de la autoridad competente en el marco de un procedimiento establecido anteriormente por ley y en el cual el migrante haya tenido la posibilidad de defenderse en concordancia con los estándares interamericanos de debido proceso.

8. Establecer por vía legal un mecanismo para que las personas que sean deportadas o repatriadas puedan iniciar o dar continuidad a acciones legales a través de sus consulados.

En materia de condiciones de detención:

1. Garantizar que las condiciones de detención de las estaciones migratorias y las estancias provisionales cumplan con los estándares mínimos de derechos humanos reconocidos en la Convención Americana y desarrollados en mayor detalle en los Principios y Buenas Prácticas sobre la Protección de las Personas Privadas de Libertad en las Américas de la CIDH.

2. Garantizar el acceso a atención médica primaria en las estaciones migratorias y en las estancias provisionales.

3. Asegurar que las personas que se encuentran bajo detención migratoria puedan mantener una comunicación expedita con sus familiares, abogados y/o tutores. Para este efecto se debe garantizar el acceso gratuito a Internet y teléfono en las estaciones migratorias y las estancias provisionales.

4. Garantizar el acceso de las organizaciones de la sociedad civil a estaciones migratorias, estancias provisionales, así como cualquier otro lugar en el que puedan ser detenidos migrantes en situación migratoria irregular, solicitantes de asilo, refugiados, apátridas y otras personas en necesidad de protección internacional para prestar asistencia humanitaria, jurídica, así como para mo- 
Esta revista forma parte del acervo de la Biblioteca Jurídica Virtual del Instituto de Investigaciones Jurídicas de la UNAM

\section{OSCAR CRUZ BARNEY}

nitorear las condiciones en que se encuentran las personas allí detenidas y las de estos lugares.

En materia de igualdad, no discriminación y derechos económicos, sociales y culturales para los migrantes en México la CIDH recomendó al Estado Mexicano:

1. Adoptar las medidas necesarias para el reconocimiento de la nacionalidad mexicana a los niños y niñas nacidos en México que sean hijos de personas migrantes, independientemente de cuál sea la situación migratoria de los padres.

2. Garantizar que los programas de regularización tengan costos bajos, existan facilidades de pago y exenciones, y se minimicen los tiempos de espera.

3. Garantizar que los trabajadores migrantes conozcan sus derechos laborales y sepan dónde acudir en caso de que estos sean vulnerados. Prestar asistencia jurídica gratuita con objeto de que los trabajadores migrantes puedan reclamar sus derechos, independientemente de su situación migratoria.

4. Perseguir y sancionar a aquellos empleadores que cometan abusos en contra de los trabajadores migrantes y sus familias, así como garantizar el acceso a los migrantes a recursos internos que aseguren su debida reparación.

5. Reforzar la protección de los trabajadores agrícolas de temporada a través del monitoreo y fiscalización en terreno de las condiciones en que desarrollan sus trabajos y asegurar que se estén desarrollando bajo contratos de trabajo formales.

6. Adoptar las medidas tendientes a garantizar los derechos económicos, sociales y culturales de los trabajadores migrantes sin discriminación alguna.

En particular, el Estado debe monitorear las condiciones de vida en las fincas o en los lugares en los que viven los trabajadores migrantes y sus familias, de forma que se les provea de suministros básicos tales como: agua potable, electricidad, servicios médicos y programas educativos.

7. Garantizar la protección de las trabajadoras domésticas a través de la fiscalización en sus lugares de trabajo y de una mayor divulgación e información de sus derechos.

8. Implementar programas de acceso a asistencia médica regular para trabajadores agrícolas migrantes y sus familias, y realizar campañas de prevención de enfermedades que afecten regularmente a esta población. 
Esta revista forma parte del acervo de la Biblioteca Jurídica Virtual del Instituto de Investigaciones Jurídicas de la UNAM

MIGRACIÓN, ATENCIÓN A REFUGIADOS Y LIBRE COMERCIO MÉXICO

9. Fortalecer los mecanismos de inserción escolar de las familias migrantes, internas y externas, en consideración a las particularidades del ciclo agrícola y las diferencias culturales.

10. Establecer procedimientos para atender a migrantes analfabetas, de nivel escolar bajo o que no hablen o entiendan el idioma español. Contar con la ayuda de traductores y cartillas de información en diversos idiomas.

\section{La Comisión Mexicana de Ayuda a Refugiados}

Cabe destacar que la Comisión Mexicana de Ayuda a Refugiados es responsable de conducir la política en materia de refugiados y protección complementaria, así como gestionar acciones de asistencia desde el inicio del procedimiento con pleno respeto a los derechos humanos. ${ }^{32}$

La comisión tiene como marco jurídico las disposiciones y convenciones siguientes:

- Constitución Política de los Estados Unidos Mexicanos.

- Convención sobre el Estatuto de los Refugiados.

- Convención Americana sobre Derechos Humanos.

- Protocolo sobre el Estatuto de los Refugiados.

- Pacto Internacional de Derechos Económicos, Sociales y Culturales.

- Pacto Internacional de Derechos Civiles y Políticos.

- Ley de Migración.

- Ley sobre Refugiados, Protección Complementaria y Asilo Político.

- Ley General de los Derechos de Niñas, Niños y Adolescentes.

- Ley para la Protección de los Derechos de Niñas, Niños y Adolescentes.

- Ley General de Transparencia y Acceso a la Información Pública.

- Ley General de Protección de Datos Personales.

- Ley Federal de Archivos.

- Ley Federal de Transparencia y Acceso a la Información Pública.

- Ley Federal de Procedimiento Contencioso Administrativo.

- Ley Federal de Procedimiento Administrativo.

- Ley Orgánica de la Administración Pública Federal.

32 Véase https://www.gob.mx/comar/que-hacemos. 
Esta revista forma parte del acervo de la Biblioteca Jurídica Virtual del Instituto de Investigaciones Jurídicas de la UNAM

\section{OSCAR CRUZ BARNEY}

- Código Federal de Procedimientos Civiles.

- Reglamento de la Ley de Migración.

- Reglamento de la Ley sobre Refugiados y Protección Complementaria.

- Reglamento Interior de la Secretaría de Gobernación.

- Manual de Organización General de la Secretaría de Gobernación.

- Manual de Organización Específico de la COMAR.

- Acuerdo por el que se crea con carácter permanente una comisión.

- Acuerdo por el que se adscriben orgánicamente los órganos administrativos desconcentrados de la SEGOB.

- Acuerdo por el que se delegan facultades para ejercer las atribuciones en materia de refugiados.

- Acuerdo del pleno del INAI, bases de interpretación.

- Acuerdo que tiene por objeto emitir disposiciones generales en materia de archivo.

Conforme el artículo 11 y 18 de la Ley sobre Refugiados, Protección Complementaria y Asilo Político y los artículos 8, 17, 18, 19 y 20 del Reglamento de la Ley sobre Refugiados y Protección Complementaria, ante la Coordinación General de la Comisión Mexicana de Ayuda a Refugiados se presenta por el extranjero la Solicitud de reconocimiento de la condición de refugiado. ${ }^{33}$

La solicitud se puede hacer mediante escrito libre sin importar el idioma o de manera verbal y la pueden presentar los extranjeros que se encuentren en territorio nacional por sí, por su representante legal o por interpósita persona. Los casos en que se puede solicitar el reconocimiento de la calidad de refugiado son cuando el extranjero que se encuentre en territorio nacional y esté en alguno de los siguientes supuestos:

1. Que debido a fundados temores de ser perseguido por motivos de raza, religión, nacionalidad, género, pertenencia a determinado grupo social u opiniones políticas, se encuentre fuera del país de su nacionalidad y no pueda o, a causa de dichos temores, no quiera acogerse a la protección de tal país; o que, careciendo de nacionalidad y hallándose, a consecuencia de tales aconteci-

33 Véase $h t t p: / / w w w . g o b . m x / c o m a r / a c c i o n e s-y$-programas/solicitud-de-reconocimientode-la-condicion-de-refugiado. Sobre el concepto de extranjero véase González Martín, Nuria, Derechos de los inmigrantes..., pp. 6 y ss. 
Esta revista forma parte del acervo de la Biblioteca Jurídica Virtual del Instituto de Investigaciones Jurídicas de la UNAM

MIGRACIÓN, ATENCIÓN A REFUGIADOS Y LIBRE COMERCIO MÉXICO

mientos, fuera del país donde antes tuviera residencia habitual, no pueda o, a causa de dichos temores, no quiera regresar a él;

2. Que ha huido de su país de origen, porque su vida, seguridad o libertad han sido amenazadas por violencia generalizada, agresión extranjera, conflictos internos, violación masiva de los derechos humanos $u$ otras circunstancias que hayan perturbado gravemente el orden público, y

3. Que debido a circunstancias que hayan surgido en su país de origen o como resultado de actividades realizadas, durante su estancia en territorio nacional, tenga fundados temores de ser perseguido por motivos de raza, religión, nacionalidad, género, pertenencia a determinado grupo social u opiniones políticas; o su vida, seguridad o libertad pudieran ser amenazadas por violencia generalizada, agresión extranjera, conflictos internos, violación masiva de los derechos humanos u otras circunstancias que hayan perturbado gravemente el orden público.

Cuando el extranjero se encuentre en territorio nacional podrá solicitar de manera verbal o escrita dentro del término de 30 días hábiles contados a partir del día siguiente al que haya ingresado al país, o en su caso, aquél en que le haya sido materialmente posible presentarla. Deberá aportar los datos de identificación y elementos para sustentar su solicitud. Cuando la solicitud sea presentada por un representante legal o interpósita persona, el solicitante deberá ratificarla personalmente y presentarse a las entrevistas que al efecto le señale la Coordinación General de la Comisión Mexicana de Ayuda a Refugiados; debiendo:

1. Proporcionar información sobre sus antecedentes personales, los cuales podrán ser verificados con las autoridades competentes.

2. Aportar con veracidad información sobre los motivos por los que salió de su país de origen o de residencia habitual y si, en su caso, proviene de un tercer país.

3. Aportar pruebas o, en su caso, explicar de manera satisfactoria la falta de las mismas.

4. Relatar las circunstancias de las razones invocadas en apoyo de su solicitud.

5. Proporcionar cualquier otra información que el entrevistador estime necesaria para esclarecer la existencia de fundados temores o amenazas en su contra.

El plazo que tiene la autoridad para responder a la solicitud es de 45 días hábiles contados a partir de la admisión de la misma. 
Esta revista forma parte del acervo de la Biblioteca Jurídica Virtual del Instituto de Investigaciones Jurídicas de la UNAM

\section{OSCAR CRUZ BARNEY}

\section{La Unidad de Investigación de Delitos para Personas Migrantes y el Mecanismo de Apoyo Exterior Mexicano de Búsqueda e Investigación}

El 18 de diciembre de 2015 se creó la Unidad de Investigación de Delitos para Personas Migrantes y el Mecanismo de Apoyo Exterior Mexicano de Búsqueda e Investigación y se establecieron sus facultades y organización mediante el ACUERDO A/117/15 de la Procuraduría General de la República. ${ }^{34}$

En su momento se señaló que "la creación de la Unidad de Investigación dentro de la Procuraduría General de la República y del Mecanismo de Búsqueda e Investigación son logros de las familias de migrantes y de organizaciones de la sociedad civil que durante más de tres años han trabajado para mejorar el acceso a la justicia para casos de migrantes en su tránsito por México. Fundación para la Justicia, junto con comités de familiares de El Salvador, Guatemala y Honduras, han sido sus principales impulsores. Estas medidas responden a recomendaciones del Sistema Interamericano y de Naciones Unidas, y facilitarán la denuncia de delitos cometidos en contra de personas migrantes, el acceso a la justicia y la búsqueda y localización independientemente del país en que se encuentran las víctimas y sus familias." 35

La creación de la Unidad obedeció en parte a que, como ya señalamos anteriormente, la Comisión Interamericana de Derechos Humanos recomendó al Estado mexicano crear una instancia especializada en el ámbito federal que se encargue de la investigación penal de los delitos y violaciones a sus derechos humanos en contra de migrantes, como se puede verificar en su publicación del año 2013 "Derechos humanos de los migrantes y otras personas en el contexto de la movilidad humana en México", ${ }^{36}$ en la que destaca que una instancia de este tipo permitiría a las personas migrantes y sus familiares, entre otros, "saber a dónde

34 La Unidad de Investigación de Delitos para Personas Migrantes y el Mecanismo de Apoyo Exterior Mexicano de Búsqueda e Investigación, tiene su domicilio en Calle de López número 12 (doce), planta baja, Colonia Centro, Delegación Cuauhtémoc, Código Postal 06050, Ciudad de México.

35 Véase https://www.macfound.org/press/country/3/crean-la-unidad-de-investigacionde-delitos-para-personas-migrantes-y-el-mecanismo-de-apoyo-exterior-mexicano-de-bus queda-e-investigacion/.

36 Comisión Interamericana de Derechos Humanos Derechos humanos de los migrantes y otras personas en el contexto de la movilidad humana en México, OEA/Ser. L/V/II., Doc. 48/13 30 de diciembre de 2013, 2013. Disponible en: http://www.estudiosdemigra cion.org/inedim2013/documentosypub/pub-ext/Informe-Migrantes-Mexico-2013.pdf. 
Esta revista forma parte del acervo de la Biblioteca Jurídica Virtual del Instituto de Investigaciones Jurídicas de la UNAM

acudir, focalizar el fenómeno para su atención e investigación, colaborar en la búsqueda de migrantes desaparecidos y en el reconocimiento de cadáveres y restos no identificados que pudiesen ser de migrantes, generar estadísticas confiables y permitiría un monitoreo de los resultados por parte de la sociedad civil". ${ }^{37}$

Asimismo se recibieron recomendaciones del Comité contra la Desaparición Forzada y el Relator Especial de Naciones Unidas sobre ejecuciones extrajudiciales, sumarias o arbitrarias, de implementar mecanismos de búsqueda de personas migrantes desaparecidas, no localizados, secuestrados o bajo cualquier forma de privación de la libertad, coordinados con los países de origen y los países de destino, así como garantizar el relevamiento de información ante mortem y su integración a la Base de Datos ante mortem-post mortem, trabajando conjuntamente con estos países para crear una base compartida de huellas, ácido desoxirribonucleico (ADN), y otros datos genéticos de personas desaparecidas, al igual que una base de datos sobre restos no identificados.

Por su parte, el Comité contra la Desaparición Forzada de las Naciones Unidas en su informe CED/C/SR.1119, 120 y 121 recomendó garantizar que las víctimas de las personas desaparecidas, independientemente del lugar en el que residan, tengan la posibilidad efectiva de obtener información y participar de las investigaciones y búsqueda de las personas desaparecidas. Asimismo, que los derechos de los migrantes deben ser respetados, protegidos y garantizados oportunamente, por lo que se considera necesaria la creación de un Mecanismo de Apoyo Exterior Mexicano de Búsqueda e Investigación para los casos de personas migrantes involucradas en la comisión de delitos o de violaciones a derechos humanos, ya sea como víctimas o como probables responsables en su tránsito por México hacia otros países o de nacionales que migran al extranjero, de conformidad con las recomendaciones de la Comisión Interamericana de Derechos Humanos, del Comité contra la Desaparición Forzada y de procedimientos especiales de Naciones Unidas, en disposiciones del derecho internacional de los derechos humanos y en el ordenamiento jurídico mexicano.

La Unidad debe buscar el pleno respeto al derecho a la libertad personal, a la integridad personal, al debido proceso y a los derechos considerados en éste, entre ellos, el derecho a la representación legal, al control judicial inmediato de la detención garantizando la presentación o comparecencia personal de la persona capturada o detenida ante la autoridad judicial competente, y a la interposición de recursos, a acceder

37 Ibidem, p. 178. 


\section{OSCAR CRUZ BARNEY}

a la justicia de manera gratuita, imparcial, pronta y expedita, a la comunicación y asistencia consular desde el momento mismo de su captura o detención, entre otros derechos.

En este sentido, el Mecanismo de Apoyo Exterior Mexicano de Búsqueda e Investigación, a través de los agregados de la Procuraduría General de la República, será la puerta de entrada para que las familias y las víctimas migrantes puedan acceder desde el país donde se encuentren, a las instituciones del Estado mexicano encargadas de investigar los delitos que se cometan en territorio mexicano contra la población migrante, y así presentar denuncias, ofrecer pruebas, ejercer los derechos y las facultades que la ley les reconoce, y facilitar su enlace con la defensoría de oficio, en caso de persona migrante imputada.

La Unidad es competente para facilitar el acceso a la justicia a las personas migrantes y a sus familias, realizar la búsqueda de personas migrantes desaparecidas, investigar y perseguir los delitos cometidos por o en contra de personas migrantes, con estricto apego a las leyes y demás disposiciones aplicables, además de dirigir, coordinar y supervisar la aplicación de acciones idóneas y efectivas para que se repare el daño a las víctimas.

La Unidad también es competente para conocer de los casos previstos en el Acuerdo de su creación respecto del refugiado o solicitante la condición del refugiado conforme a lo establecido en los tratados internacionales ratificados por el Estado mexicano, en particular la Convención sobre el Estatuto de los Refugiados; también personas solicitantes de asilo y a las personas apátridas y beneficiarias de protección complementaria, así como a los mexicanos deportados de otros países, que permanezcan en zonas fronterizas o distintas a su lugar de origen o residencia, siempre que se encuentren en situación de calle y condiciones de vulnerabilidad.

La Unidad está adscrita a la Subprocuraduría de Derechos Humanos, Prevención del Delito y Servicios a la Comunidad.

Se entiende por persona migrante para los efectos del Acuerdo, a quien ingresa o transita por territorio mexicano en condiciones de vulnerabilidad, ya sea a través de puertos, aeropuertos, fronteras, puntos de control de las migraciones, cruces informales y cualquiera otros recorridos que hagan las personas migrantes; y se trate de:

1. Extranjero indocumentado o sin permiso o visa válida.

2. Extranjero o mexicano, con o sin documento o visa válidos, que transita por territorio mexicano hacia otro país. Para efectos del tránsito, es irrelevante la temporalidad de la estancia en territorio mexicano. 
Esta revista forma parte del acervo de la Biblioteca Jurídica Virtual del Instituto de Investigaciones Jurídicas de la UNAM

3. Trabajadores migratorios y sus familiares conforme a los tratados internacionales ratificados por el Estado mexicano, en particular lo dispuesto en los artículos 10. y 2o. de la Convención Internacional sobre la Protección de los Derechos de Todos los Trabajadores Migratorios y de sus Familiares; y en el artículo 3o., fracción XVII, de la Ley de Migración, y

4. Toda persona que migra por un conflicto armado, violaciones a los derechos humanos, desplazamiento forzado, persecución o por otras formas de violencia, por razones económicas, porque es víctima de trata de personas, o por cualquier otro motivo que ponga en riesgo los derechos humanos o bienes jurídicos de quien migra o de su familia.

El titular de la Unidad será designado y removido libremente por la titular de la Procuraduría General de la República y deberá reunir los requisitos siguientes:

1. Ser ciudadano mexicano, en pleno ejercicio de sus derechos.

2. Tener cuando menos treinta y cinco años cumplidos el día de la designación.

3. Contar con título de licenciatura en derecho.

4. Contar con experiencia acreditada en las materias relacionadas con el objeto de la Unidad, en especial en derecho internacional de los derechos humanos, atención a víctimas y derechos de las personas migrantes.

5. Ser de notoria buena conducta y no haber sido condenado, mediante sentencia irrevocable, como responsable de un delito doloso, ni haber figurado como responsable de violaciones de derechos humanos en resoluciones con efectos de sentencia de organismos de protección de los derechos humanos, y

6. No estar suspendido ni haber sido destituido o inhabilitado por resolución firme como servidor público.

El titular de la Unidad tiene la calidad de agente del Ministerio Público de la Federación, y tendrá competencia para conocer de los casos a que se refiere el Acuerdo, en términos de las disposiciones jurídicas aplicables. Asimismo tiene las facultades siguientes:

1. Ejercer las atribuciones que la Constitución Política de los Estados Unidos Mexicanos, el artículo 4o., fracciones I, IV, V, VII y IX, de la Ley Orgánica de la Procuraduría General de la República, la Ley de Migración y demás disposiciones jurídicas confieren al Ministerio Público de la Federación en materia de delitos de com- 
Esta revista forma parte del acervo de la Biblioteca Jurídica Virtual del Instituto de Investigaciones Jurídicas de la UNAM

petencia federal cometidos por o en contra de las personas a que se refieren los artículos primero y tercero de este Acuerdo.

2. Garantizar, en el ámbito de procuración de justicia de su competencia, el respeto a los derechos que reconocen la Constitución Política de los Estados Unidos Mexicanos, los tratados internacionales en la materia de los que el Estado mexicano sea parte, la Ley General de Víctimas, la Ley General de los Derechos de Niñas, Niños y Adolescentes, y demás disposiciones jurídicas aplicables a las personas a que se refiere el artículo primero de este Acuerdo.

3. Distinguir, previa investigación, si se está ante un probable responsable o si se trata de una posible víctima de trata de personas o un sujeto solicitante de la condición de refugiado o asilado. Para el desarrollo de esta facultad se sujetará a lo dispuesto en el protocolo que para tal efecto se emita y en el caso de personas refugiadas deberá velar por el cumplimiento de los tratados internacionales ratificados por el Estado mexicano en la materia, en particular la Convención sobre el Estatuto del Refugiado.

4. Remitir a los órganos especializados del sistema integral de justicia especializado para adolescentes previsto en el artículo 18 de la Constitución Política de los Estados Unidos Mexicanos, la investigación de delitos cometidos por y en contra de personas migrantes, cuando el posible sujeto activo sea un adolescente.

5. Ejercer la facultad de atracción de los delitos del fuero común cometidos en contra de o por personas migrantes cuando estos tengan conexidad con delitos federales.

6. Concentrar las investigaciones iniciadas en la materia a efecto de realizar una investigación integral de los hechos.

7. Llevar a cabo las acciones de búsqueda y localización de personas desaparecidas, así como de protección a víctimas del delito materia de su competencia y aplicar los protocolos en la materia.

8. Hacer del conocimiento de la autoridad competente en forma inmediata la información relativa a la desaparición, secuestro, o cualquier forma de privación ilegal de libertad de una persona migrante que constituya un delito cuya investigación sea competencia del fuero común, y cuando aquélla lo solicite, cooperará en las investigaciones, en términos de las disposiciones aplicables y los acuerdos respectivos.

9. Requerir el apoyo y establecer estrategias de coordinación con las policías, para realizar la búsqueda de personas migrantes desaparecidas. 
Esta revista forma parte del acervo de la Biblioteca Jurídica Virtual del Instituto de Investigaciones Jurídicas de la UNAM

10. Requerir y coordinarse con las instancias pertinentes, para que se realicen las actuaciones necesarias para la búsqueda y localización de personas migrantes privadas de la libertad, desaparecidas o cuyo paradero se desconozca; los desplazamientos y búsquedas en terreno que sean necesarias para el éxito de la localización, así como llevar a cabo acciones estratégicas de difusión, generales y específicas, con fines de localización como lo son el establecer comisiones de búsqueda, auxiliarse de los medios masivos de comunicación y realizar todas las acciones necesarias para dar a conocer los datos y descripción de la persona buscada, a fin de lograr el paradero de la misma. Las estrategias de difusión específicas que se soliciten requerirán el consentimiento informado y expreso de los familiares de la persona migrante desaparecida.

11. Proponer la celebración de acuerdos de colaboración o convenios, para que conforme a la legislación aplicable el Ministerio Público de la Federación tenga libre e inmediato acceso a todo centro o lugar de detención, y los familiares de migrantes desaparecidos puedan tener acceso a los mismos de conformidad con los lineamientos que se expidan.

12. Autorizar las determinaciones de incompetencia, acumulación y separación de las investigaciones y, previo dictamen del agente del Ministerio Público de la Federación Auxiliar de la Procuraduría, la reserva y en definitiva el no ejercicio de la acción penal, de conformidad con las disposiciones procesales penales aplicables.

13. Autorizar la solicitud del desistimiento de la acción penal; de la cancelación de la orden de aprehensión; el sobreseimiento; la suspensión del proceso; la formulación de conclusiones no acusatorias; las medidas cautelares; la solicitud de intervención de comunicaciones privadas; autorizar la realización de entregas vigiladas y operaciones encubiertas; requerir la localización geográfica en tiempo real, o bien la conservación inmediata de datos contenidos en redes, sistemas o equipos informáticos; y demás de conformidad con la legislación procesal penal aplicable.

14. Solicitar a la Comisión Mexicana de Ayuda a Refugiados que evalúe el caso particular para el reconocimiento de la calidad de solicitante de la condición de refugiado, calidad de condición de refugiado o calidad para que sea beneficiario de protección complementaria, cuando la persona migrante sea víctima de delitos graves o cuando la devolución de ésta a su país de origen o al 
Esta revista forma parte del acervo de la Biblioteca Jurídica Virtual del Instituto de Investigaciones Jurídicas de la UNAM

lugar en donde residía, amenace contra su vida, integridad personal, seguridad o libertad.

15. Resolver en definitiva las consultas que agentes del Ministerio Público de la Federación formulen a las prevenciones que la autoridad judicial acuerde en los términos que la ley disponga respecto de la omisión de formular conclusiones en el plazo legal, de conclusiones presentadas en un proceso penal, o de actos cuya consecuencia sea el sobreseimiento del proceso o la libertad absoluta del inculpado antes de que se pronuncie sentencia; de cancelación o reclasificación de órdenes de aprehensión en los términos previstos por la legislación procesal penal aplicable.

16. Formular los requerimientos de información y de documentos relativos al sistema financiero o de naturaleza fiscal, en coordinación con la unidad administrativa competente de la institución, conforme a las disposiciones procesales penales aplicables.

17. Requerir la información que resulte necesaria para el ejercicio de sus funciones; entre la que destaca la contenida en registros y bases de datos, así como la correspondiente a las áreas de investigación policial, tecnológica, científica y pericial.

18. Realizar, en coordinación con la unidad administrativa competente, el análisis criminal y de reconstrucción y recreación de contextos, de los casos bajo su competencia, con el objeto de generar información relevante para la investigación e imputación.

19. Coadyuvar en la atención y seguimiento de las solicitudes de información materia de su competencia.

20. Solicitar, en coordinación con la unidad administrativa responsable, a las autoridades competentes cuando así corresponda la autorización para realizar exhumaciones en cementerios, fosas clandestinas $u$ otros sitios en los que se localicen o se tengan razones fundadas para creer que se encuentran cuerpos o restos de víctimas migrantes; garantizar el respeto de los derechos de los familiares de la persona migrante desaparecida y velar por la preservación de los elementos probatorios indispensables para llegar a la identificación de la persona, el esclarecimiento del hecho y la posterior individualización de los responsables, de ser el caso.

21. Coordinarse con las unidades administrativas y órganos desconcentrados de la institución a efecto de hacer efectivas y eficientes sus labores de investigación y búsqueda de personas migrantes.

22. Atender e informar, en coordinación con la unidad administrativa competente, a los familiares de migrantes que hayan sido víc- 
Esta revista forma parte del acervo de la Biblioteca Jurídica Virtual del Instituto de Investigaciones Jurídicas de la UNAM

timas de delitos, de las líneas de investigación orientadas a la localización de estos e incorporarlos en los procesos destinados a la búsqueda y localización de sus familiares, permitiendo su efectiva participación dentro de los mismos, de conformidad con las disposiciones aplicables.

23. Coordinarse con las autoridades competentes para la búsqueda de ciudadanos mexicanos migrantes desaparecidos en el extranjero, de acuerdo con sus investigaciones.

24. Coordinar a los agentes del Ministerio Público de la Federación designados para investigar los delitos relacionados con personas migrantes, y requerir la colaboración de aquellos que se encuentran adscritos a las delegaciones o equivalentes de la Procuraduría, debiendo en su caso atraer las investigaciones iniciadas por estos cuando así se requiera.

25. Coordinarse con las instituciones de procuración de justicia de las entidades federativas, en términos de los convenios de colaboración celebrados en la Conferencia Nacional de Procuración de Justicia, a fin de colaborar con las autoridades federales y locales en la búsqueda y localización de personas migrantes desaparecidas.

26. Solicitar, con base en el programa de trabajo correspondiente, a las autoridades competentes, a través de la Coordinación de Asuntos Internacionales y Agregadurías, se activen los mecanismos de cooperación y asistencia con las autoridades de otros países que realicen investigaciones relacionadas con el género de delitos a que se refiere este Acuerdo.

27. Notificar, en los términos previstos en los tratados internacionales ratificados por el Estado mexicano en la materia, a la autoridad consular del país que corresponda, cuando se inicie una investigación donde se encuentre implicada una persona migrante extranjera y cumplir con las obligaciones que establecen las disposiciones aplicables en la materia, garantizando en todo momento la protección de sus derechos humanos.

28. Solicitar el apoyo de la Coordinación de Asuntos Internacionales y Agregadurías, cuando la gestión requiera de la formulación de una asistencia jurídica internacional, así como cuando se necesite que los agregados, en su carácter de auxiliares del Ministerio Público de la Federación, realicen las acciones que les sean requeridas para el cumplimiento del objeto del presente Acuerdo, e informen a la Unidad sobre su cumplimiento. 
Esta revista forma parte del acervo de la Biblioteca Jurídica Virtual del Instituto de Investigaciones Jurídicas de la UNAM

\section{OSCAR CRUZ BARNEY}

29. Establecer, en coordinación con las unidades administrativas competentes de la institución, mecanismos de cooperación y colaboración con autoridades federales, del Distrito Federal, estatales y municipales, en el ámbito de su competencia, atendiendo a las normas y políticas institucionales; así como con la Comisión Nacional de los Derechos Humanos, organismos públicos de derechos humanos de las entidades federativas y con las organizaciones no gubernamentales dedicadas a la defensa de los derechos humanos, todo ello en el ejercicio de sus funciones.

30. Solicitar la colaboración de la Agencia de Investigación Criminal, para que a través de la Policía Federal Ministerial, el Centro Nacional de Planeación, Análisis e Información para el Combate a la Delincuencia y la Coordinación General de Servicios Periciales le brinde apoyo oportuno.

31. Generar mecanismos de acercamiento a aquellos lugares de mayor concentración o tránsito de personas migrantes, con el fin de brindarles apoyo, asistencia y ayuda, en el ámbito de su competencia.

32. Informar a las personas migrantes víctimas o testigos de delitos graves cometidos en territorio nacional sobre los derechos que les asisten de retornar a su país de origen o permanecer en territorio nacional, de conformidad con el artículo 113 de la Ley de Migración y, en su caso, de solicitar la condición de visitante por razones humanitarias en términos del artículo 52, fracción $\mathrm{V}$, inciso a, de dicha ley, así como requerir a la autoridad competente un informe de las acciones que haya realizado respecto de su canalización a las instituciones públicas o privadas especializadas para brindarles la atención correspondiente.

33. Expedir las constancias correspondientes cuando en la investigación obren documentos de identificación de personas migrantes, detallando la naturaleza de los mismos y su vigencia, para los efectos legales conducentes.

34. Reconocer la calidad de víctima en una investigación o proceso penal, lo cual podrá surtir los efectos de lo previsto en el artículo 101, fracción III, de la Ley General de Víctimas.

35. Consultar el registro administrativo de la detención, previsto en la Ley General del Sistema Nacional de Seguridad Pública, con el fin de fortalecer las acciones de búsqueda de personas migrantes desaparecidas.

36. Remitir al registro administrativo de la detención, por conducto de la unidad administrativa competente, los datos de las personas 
Esta revista forma parte del acervo de la Biblioteca Jurídica Virtual del Instituto de Investigaciones Jurídicas de la UNAM

MIGRACIÓN, ATENCIÓN A REFUGIADOS Y LIBRE COMERCIO MÉXICO

migrantes detenidas con motivo de un delito de los que se refiere el presente Acuerdo, identificando su nacionalidad o su calidad de extranjero y, en su caso, edad, sexo, domicilio, zona o país de origen y fotografía.

37. Promover la celebración de acuerdos y convenios de colaboración para la transferencia de información que detenten respecto de personas migrantes que se encuentren en centros hospitalarios, psiquiátricos y demás instituciones públicas.

38. Promover una cultura de prevención del delito, de respeto y difusión de los derechos relacionados con las personas migrantes.

39. Presentar al titular de la Subprocuraduría de Derechos Humanos, Prevención del Delito y Servicios a la Comunidad, el proyecto de lineamientos de operación del Mecanismo de Apoyo Exterior, para su expedición, previa consulta con la Coordinación de Asuntos Internacionales y Agregadurías.

40. Proponer a la titular de la Procuraduría General de la República los manuales de organización, procedimientos y servicios al público, en el ámbito de su competencia, y

41. Las demás facultades que le otorgue la Procuradora General de la República.

La Unidad podrá ejercer la facultad de atracción a que se refiere la fracción $V$ del artículo anterior. En ese caso y para tal efecto deberán concurrir los requisitos siguientes:

1. Que el delito de que se trate sea de competencia del orden común, cuando sean conductas conexas con delitos federales.

2. Que el sujeto pasivo o activo del delito sea una persona migrante, de conformidad con las disposiciones de este Acuerdo, y

3. Que el delito de que se trate sea sancionado con pena privativa de la libertad.

El Mecanismo de Apoyo Exterior contemplará un conjunto de acciones y medidas tendientes a facilitar el acceso a la justicia y el ejercicio de acciones para la reparación del daño, en el ámbito de su competencia, a personas migrantes o sus familias que se encuentren en otro país y requieran acceder directamente a las instituciones objeto del presente instrumento establecidas en el ordenamiento jurídico mexicano, coadyuvar en la búsqueda de personas migrantes desaparecidas y en la investigación y persecución de los delitos que realice la Unidad, así como para garantizar los derechos reconocidos por el orden jurídico nacional en favor de las víctimas y ofendidos del delito. 
El Mecanismo de Apoyo Exterior estará a cargo de la Unidad y funcionará mediante la colaboración que establezca ésta con la Coordinación de Asuntos Internacionales y Agregadurías, las agregadurías así como con las unidades administrativas y órganos desconcentrados de la institución y regirá su actuación a través de los lineamientos que para tal efecto se expidan.

El titular de la Unidad en coordinación con la unidad administrativa competente de la institución, presentará un informe público anual estadístico, el cual deberá comprender número de casos atendidos y lugar de incidencia, promedios de edad, nacionalidad y sexo de la población atendida o víctima; número de víctimas atendidas y medidas de atención y seguimiento promovidas, en su caso el tipo de delito, personas detenidas o consignadas, casos concluidos y motivo de conclusión, número de sentencias emitidas y delitos por los cuales se emite la sentencia, y el número tipo de reparaciones de daños determinadas en sentencias.

Para la toma de muestras, comunicación de la identificación de restos forenses y procesos de restitución de restos, se solicitará la colaboración de la Agencia de Investigación Criminal por conducto de la Coordinación General de Servicios Periciales, así como de la Coordinación de Asuntos Internacionales y Agregadurías para que a través de estas últimas se puedan gestionar las diligencias requeridas, de conformidad con las disposiciones jurídicas aplicables.

En el caso de requerir la comparación de información con bancos de datos forenses de otro país, el titular de la Unidad solicitará el apoyo de la Coordinación de Asuntos Internacionales y Agregadurías y, en su caso, de la autoridad competente para que se solicite la colaboración de las instituciones extranjeras respectivas, de conformidad con las disposiciones jurídicas aplicables.

Para las diligencias ministeriales de comunicación y entrega de restos, se actuará conforme a los protocolos de actuación en la materia.

A solicitud de las personas a que se refieren los artículos primero y tercero del presente Acuerdo, y de las víctimas o sus familiares que se encuentren en otro país, los titulares de las agregadurías de la institución, en su carácter de auxiliares del Ministerio Público de la Federación, y como parte del Mecanismo de Apoyo Exterior, deberán realizar las acciones siguientes:

1. Recibir las denuncias de los hechos probablemente constitutivos de delito y se hayan perpetrado en territorio nacional, así como las pruebas respecto de las investigaciones y denuncias correspondientes, a efecto de que dicha información sea canalizada 
Esta revista forma parte del acervo de la Biblioteca Jurídica Virtual del Instituto de Investigaciones Jurídicas de la UNAM

MIGRACIÓN, ATENCIÓN A REFUGIADOS Y LIBRE COMERCIO MÉXICO

con las formalidades de ley a la unidad administrativa que resulte competente, para su trámite correspondiente.

2. Recibir las solicitudes de búsqueda de personas migrantes desaparecidas en territorio mexicano e informar por escrito el resultado de la búsqueda.

3. Solicitar, en el ámbito de sus atribuciones, acciones de búsqueda in situ en las que podrán participar víctimas y organizaciones de la sociedad civil, en lugares donde se tenga información de la posible existencia de personas migrantes desaparecidas.

4. Canalizar ante las autoridades competentes las solicitudes de inscripción de una víctima en el Registro Nacional de Víctimas, y todas aquellas relativas al ejercicio de las medidas y derechos reconocidos en la Ley General de Víctimas.

5. Gestionar ante las autoridades competentes que un abogado defensor o asesor jurídico les asista desde territorio nacional, debiéndose garantizar la correcta y efectiva comunicación entre ambas partes, de conformidad con las disposiciones jurídicas aplicables.

6. Informar de las actuaciones que se llevarán a cabo en las investigaciones y en el proceso, con inclusión de la fecha de las audiencias o su aplazamiento y la fecha programada en que se emitirán resoluciones y sentencias.

7. Solicitar a las autoridades competentes un traductor o intérprete en la lengua y cultura respectiva, de conformidad con el artículo 20. de la Constitución Política de los Estados Unidos Mexicanos, para ejercer sus derechos de víctima o imputado. En los casos en los que el traductor o intérprete se deba proporcionar a una persona extranjera en las instalaciones de la Agregaduría, realizará las gestiones ante las autoridades del país que corresponda, a efecto de solicitar la asistencia del traductor o intérprete, y

8. Gestionar copia de las investigaciones conforme a lo dispuesto en la legislación procesal penal aplicable.

El titular de la Unidad podrá reunirse para la entrega de sus informes con comités o grupos de familiares de las víctimas migrantes, y podrán participar, a petición de estos, organizaciones de la sociedad civil con el objeto de presentar recomendaciones o sugerencias de acciones para el fortalecimiento del funcionamiento de la Unidad y del Mecanismo de Apoyo Exterior.

La inobservancia de lo dispuesto en el presente Acuerdo por parte de los servidores públicos de la institución, los hará acreedores a las sanciones que establece la Ley Orgánica de la Procuraduría General de 
Esta revista forma parte del acervo de la Biblioteca Jurídica Virtual del Instituto de Investigaciones Jurídicas de la UNAM

\section{OSCAR CRUZ BARNEY}

la República, la Ley Federal de Responsabilidades Administrativas de los Servidores Públicos y demás disposiciones aplicables, sin perjuicio de la responsabilidad penal a que hubiere lugar.

\section{LA LEY SOBRE REFugIAdos, PROTECCIÓN COMPLEMENTARIA Y ASILO POLÍTICO}

La ley, publicada en el Diario Oficial de la Federación el 27 de enero de 2011, tiene por objeto regular el otorgamiento de asilo político, el reconocimiento de la condición de refugiado y el otorgamiento de protección complementaria, así como establecer las bases para la atención a los solicitantes y asistencia a los asilados y refugiados que se encuentran en territorio nacional, con la finalidad de garantizar el pleno respeto a sus derechos humanos.

La secretaría en la aplicación e interpretación de la Ley deberá observar las disposiciones de la Constitución Política de los Estados Unidos Mexicanos, los tratados internacionales de observancia obligatoria en México y demás ordenamientos aplicables, sin perjuicio de la intervención de otras autoridades de conformidad con las disposiciones antes referidas y demás aplicables.

Define asilo político como la protección que el Estado mexicano otorga a un extranjero considerado perseguido por motivos o delitos de carácter político o por aquellos delitos del fuero común que tengan conexión con motivos políticos, cuya vida, libertad o seguridad se encuentre en peligro, el cual podrá ser solicitado por vía diplomática o territorial. En todo momento se entenderá por asilo el asilo político.

Considera asimismo que el concepto de fundados temores se refiere a los actos y hechos que den o hayan dado lugar a una persecución, y que por su naturaleza, carácter reiterado, o bien, por una acumulación de acciones por parte de un tercero, ponen o podrían poner en riesgo la vida, la libertad o la seguridad de una persona.

La Ley contempla la denominada protección complementaria, entendiendo por tal protección que la Secretaría de Gobernación otorga al extranjero que no ha sido reconocido como refugiado en los términos de la presente Ley, consistente en no devolverlo al territorio de otro país en donde su vida, se vería amenazada o se encontraría en peligro de ser sometido a tortura u otros tratos o penas crueles, inhumanos o degradantes.

La condición de Refugiado es el estatus jurídico del extranjero que encontrándose en los supuestos establecidos en el artículo 13 de la Ley, 
Esta revista forma parte del acervo de la Biblioteca Jurídica Virtual del Instituto de Investigaciones Jurídicas de la UNAM

es reconocido como refugiado, por la Secretaría de Gobernación y recibe protección como tal.

La ley distingue entre solicitante de asilo político quien es el extranjero que solicita a la Secretaría de Relaciones Exteriores, a sus delegaciones localizadas fuera del Distrito Federal o a la Representación, según corresponda, el otorgamiento de asilo político y el solicitante de la condición de refugiado quien es el extranjero que solicita a la Secretaría el reconocimiento de la condición de refugiado, independientemente de su situación migratoria.

En aplicación de la Ley se deberán observar, entre otros, los siguientes principios y criterios:

1. No devolución.

2. No discriminación.

3. Interés superior del niño.

4. Unidad familiar.

5. No sanción por ingreso irregular, y

6. Confidencialidad.

Se establece que ningún solicitante o refugiado podrá en modo alguno ser rechazado en frontera o devuelto de cualquier forma al territorio de otro país donde su vida peligre por los motivos señalados en la propia ley (artículo 13) o en donde existan razones fundadas para considerar que estaría en peligro de ser sometido a tortura u otros tratos o penas crueles, inhumanos o degradantes. El extranjero al que se le otorgue protección complementaria no podrá ser devuelto al territorio de otro país donde su vida peligre o en donde existan razones fundadas para considerar que estaría en peligro de ser sometido a tortura u otros tratos o penas crueles, inhumanos o degradantes.

No se impondrá sanción alguna por motivo de su ingreso irregular al país, al refugiado o al extranjero que se le otorgue protección complementaria. En caso de haberse iniciado procedimiento migratorio por ingreso irregular al territorio nacional a un solicitante, dicho procedimiento se suspenderá hasta que se emita una resolución sobre el reconocimiento de la condición de refugiado. En cualquier caso, los procedimientos migratorios serán concluidos considerando la resolución sobre la solicitud de reconocimiento de la condición de refugiado.

En el reconocimiento de la condición de refugiado deberá protegerse la organización y el desarrollo de la familia, así como el interés superior del niño.

Todo extranjero que se encuentre en territorio nacional tiene derecho a solicitar, por sí, por su representante legal o por interpósita per- 
Esta revista forma parte del acervo de la Biblioteca Jurídica Virtual del Instituto de Investigaciones Jurídicas de la UNAM

\section{OSCAR CRUZ BARNEY}

sona, el reconocimiento de la condición de refugiado. Si el extranjero solicitase dicho reconocimiento a través de su representante legal o por interpósita persona, deberá de ratificar su solicitud ante la Secretaría dentro del término de tres días hábiles. Si el extranjero la ratifica se continuará el procedimiento de reconocimiento, en caso contrario, se tendrá por no presentada la solicitud. El procedimiento de reconocimiento de la condición de refugiado sólo podrá continuarse por el solicitante o por su representante legal de conformidad con lo establecido en esta Ley y su reglamento.

La Secretaría reconocerá la condición de refugiado, mediante un acto declarativo, a los extranjeros que se encuentren en cualquiera de los supuestos establecidos en el artículo 13 de esta Ley, y que por tanto serán sujetos de los derechos y obligaciones contenidos en la misma. Al cónyuge, concubinario, concubina, hijos, parientes consanguíneos hasta el cuarto grado, parientes consanguíneos del cónyuge, concubinario, concubina, hasta el segundo grado que dependan económicamente del solicitante principal, que de igual forma se encuentren en territorio nacional con el solicitante, se les reconocerá por derivación la condición de refugiado. En los casos en los cuales no exista prueba documental de una relación de filiación y dependencia se analizarán otras fuentes de evidencia, incluyendo la declaración del solicitante.

Conforme al multicitado artículo 13, la condición de refugiado se reconocerá a todo extranjero que se encuentre en territorio nacional, bajo alguno de los siguientes supuestos:

1. Que debido a fundados temores de ser perseguido por motivos de raza, religión, nacionalidad, género, pertenencia a determinado grupo social u opiniones políticas, se encuentre fuera del país de su nacionalidad y no pueda o, a causa de dichos temores, no quiera acogerse a la protección de tal país; o que, careciendo de nacionalidad y hallándose, a consecuencia de tales acontecimientos, fuera del país donde antes tuviera residencia habitual, no pueda o, a causa de dichos temores, no quiera regresar a él.

2. Que ha huido de su país de origen, porque su vida, seguridad o libertad han sido amenazadas por violencia generalizada, agresión extranjera, conflictos internos, violación masiva de los derechos humanos $u$ otras circunstancias que hayan perturbado gravemente el orden público, y

3. Que debido a circunstancias que hayan surgido en su país de origen o como resultado de actividades realizadas, durante su estancia en territorio nacional, tenga fundados temores de ser 
Esta revista forma parte del acervo de la Biblioteca Jurídica Virtual del Instituto de Investigaciones Jurídicas de la UNAM

perseguido por motivos de raza, religión, nacionalidad, género, pertenencia a determinado grupo social u opiniones políticas, o su vida, seguridad o libertad pudieran ser amenazadas por violencia generalizada, agresión extranjera, conflictos internos, violación masiva de los derechos humanos u otras circunstancias que hayan perturbado gravemente el orden público. Los refugiados reconocidos bajo estos supuestos que previo a su reconocimiento hayan generado derechos de residencia, podrán optar por mantener su situación migratoria o acogerse a lo dispuesto por esta Ley y su reglamento.

Conforme al artículo 18 de la Ley el extranjero que solicite ser reconocido como refugiado deberá presentar por escrito su solicitud ante la Secretaría (se presenta ante la Coordinación General de la Comisión Mexicana de Ayuda a Refugiados) dentro del término de 30 días hábiles contados a partir del día hábil siguiente al que haya ingresado al país o, en su caso, a aquél en que le haya sido materialmente posible presentarla en los términos que defina el reglamento. En el supuesto previsto en el artículo 13, fracción III, el plazo para presentar la solicitud correrá a partir del día siguiente al que tenga conocimiento de los hechos a los que alude dicha disposición. En el caso en que al solicitante no le sea posible presentar la solicitud por escrito, la presentará verbalmente, debiéndose asentar en un acta las manifestaciones del solicitante. Si el extranjero no tiene posibilidad de comunicarse verbalmente, se tomarán las medidas necesarias para asentar en el acta correspondiente las manifestaciones del solicitante. En el supuesto de que el extranjero no comprenda el idioma español, se procederá conforme a lo establecido por el último párrafo del artículo 23 de la Ley. El procedimiento para el reconocimiento de la condición de refugiado será gratuito.

El solicitante tendrá derecho a recibir información clara, oportuna y gratuita sobre el procedimiento de reconocimiento de la condición de refugiado y sobre los derechos inherentes al mismo, así como los recursos que esta Ley y otras le concedan. Durante el procedimiento, la Secretaría tomará las medidas necesarias para garantizar el otorgamiento de asistencia institucional a los solicitantes que requieran atención especial, así como mujeres embarazadas, niñas, niños y adolescentes, personas adultas mayores, con discapacidad, enfermos crónicos, víctimas de tortura $u$ otros tratos o penas crueles, inhumanos o degradantes, de abuso sexual y violencia de género, de trata de personas o a cualquier otra persona que pudiese encontrarse en situación de vulnerabilidad de conformidad con las disposiciones jurídicas que resulten aplicables en cada materia. Cuando un solicitante en situación de vulnerabilidad haya 
sido admitido provisionalmente o se encuentre en alguna estación migratoria, la Secretaría valorará las medidas que mejor favorezcan al solicitante, de conformidad con las circunstancias del caso. En el caso de niñas, niños y adolescentes deberá determinarse su interés superior.

Cuando un extranjero que se encuentre en alguno de los lugares destinados al tránsito internacional de personas, o sujeto a un procedimiento administrativo migratorio, sin importar la etapa de dicho procedimiento, o bien, carezca de documentación que acredite su situación migratoria regular en el territorio nacional, solicite el reconocimiento de la condición de refugiado, la Secretaría deberá dictar las medidas que resulten estrictamente necesarias en cada caso, de conformidad con el reglamento. La presentación de la solicitud de un extranjero no dejará sin efectos las medidas que se hayan dictado con anterioridad a la solicitud. Cualquier autoridad que tenga conocimiento de la pretensión de un extranjero de solicitar el reconocimiento de la condición de refugiado, deberá dar aviso por escrito y de manera inmediata a la Secretaría. El incumplimiento de lo anterior será sancionado conforme a las disposiciones aplicables en materia de responsabilidades de los servidores públicos. Una vez presentada formalmente la solicitud, ninguna autoridad podrá proporcionar información o notificar a las autoridades diplomáticas o consulares del país de origen del solicitante, a menos que se cuente con evidencia del consentimiento expreso de éste. Durante el procedimiento el solicitante podrá promover por sí o a través de su representante legal. Si el solicitante se encuentra en alguna estación migratoria, se deberán tomar las medidas para garantizar la comunicación con su representante legal o, en su caso, con la persona de su confianza de conformidad con las disposiciones aplicables. En todo momento las entrevistas se deberán desahogar de manera personal con el solicitante, pudiendo estar acompañado por su representante legal.

La Secretaría deberá expedir a cada solicitante y a sus dependientes una constancia de trámite respecto de la solicitud de reconocimiento de la condición de refugiado.

Conforme al artículo 23 el solicitante deberá aportar sus datos de identificación completos y verídicos, los motivos en los cuales basa su solicitud, así como todos los elementos de los que disponga para sustentarla. Desde la presentación de la solicitud hasta antes de que la Secretaría emita resolución, el solicitante podrá aportar todas las pruebas que a su derecho convengan. La Secretaría, tomando en consideración el contexto social y cultural de donde provenga el solicitante, así como su edad, género y otras circunstancias particulares, realizará de manera personal las entrevistas que resulten necesarias, a fin de allegarse 
Esta revista forma parte del acervo de la Biblioteca Jurídica Virtual del Instituto de Investigaciones Jurídicas de la UNAM

de elementos para el análisis de su solicitud. En la substanciación del procedimiento, especialmente durante el desarrollo de las entrevistas, en caso de ser necesario se contará con el apoyo de un traductor o intérprete y de los especialistas que se requieran para facilitar la comunicación con el solicitante, mismos que en todo momento deberán de preservar la confidencialidad de la información.

La Secretaría debe analizar y evaluar todas las solicitudes de reconocimiento de la condición de refugiado y deberá emitir, en cada caso, resolución escrita, fundada y motivada, dentro de los 45 días hábiles contados a partir del día siguiente a la presentación de la solicitud. Para los efectos del párrafo anterior, la Secretaría solicitará opinión sobre las condiciones prevalecientes en el país de origen del solicitante a la Secretaría de Relaciones Exteriores y a las demás autoridades competentes que establezca el reglamento respecto de los antecedentes del solicitante. Dicha opinión deberá emitirse dentro de los quince días hábiles siguientes, contados a partir del siguiente al que se recibió la misma; si transcurrido dicho plazo, la Secretaría no recibiese la opinión solicitada, se entenderá que no existe opinión o información alguna sobre el particular.

El plazo para emitir la resolución podrá ampliarse hasta por un período igual a juicio de la Secretaría, sólo en los siguientes casos:

1. La falta de información respecto de los hechos en que se basa la solicitud.

2. La falta de traductor o especialistas que faciliten la comunicación con el solicitante.

3. La imposibilidad de realizar entrevistas en razón de las condiciones de salud del solicitante.

4. La petición del extranjero para aportar elementos que sustenten su solicitud, o

5. Cualquier otra circunstancia derivada del caso fortuito o fuerza mayor que imposibilite a la Secretaría el adecuado desarrollo del procedimiento (artículo 25).

La resolución deberá ser notificada por escrito al solicitante. La Secretaría al momento de realizar las notificaciones procurará que el solicitante comprenda el sentido de la resolución. En los casos de reconocimiento de la condición de refugiado, la Secretaría expedirá el documento migratorio correspondiente que acredite su situación migratoria regular en el país en los términos de las disposiciones aplicables. Si la resolución fuese en sentido negativo, el extranjero podrá interponer recurso de revisión ante la Coordinación General de la Comisión Mexicana 


\section{OSCAR CRUZ BARNEY}

de Ayuda a Refugiados (conforme a la fracción XIX del artículo 15 del Reglamento de la Ley Sobre Refugiados y Protección Complementaria) dentro de los 15 días hábiles contados a partir de la notificación respectiva, de conformidad con lo establecido en el reglamento; de igual forma el extranjero podrá interponer los medios de defensa que estime pertinentes, de conformidad con las disposiciones aplicables. Artículo 26. El reconocimiento de la condición de refugiado es individual. En caso de presentarse un ingreso masivo a territorio nacional de un grupo de personas que se encuentren en los supuestos previstos en el artículo 13 de la Ley y dicha situación produzca un incremento sustancial de las solicitudes de reconocimiento de la condición de refugiado, la Secretaría podrá fijar los lineamientos que se seguirán para atenderlos como grupo, en tanto no existan elementos que aconsejen su atención en lo individual. Una vez atendido el ingreso masivo, tan pronto le sea posible a la Secretaría, procederá a la determinación individual de la condición de refugiado.

Cabe destacar que conforme al artículo 27 de la ley, no será reconocida la condición de refugiado al extranjero respecto del cual, una vez analizada su solicitud, existan motivos fundados para considerar que se encuentra en alguno de los supuestos siguientes:

1. Que ha cometido un delito contra la paz, el crimen de genocidio, crímenes de lesa humanidad o crímenes de guerra, de los definidos en los instrumentos internacionales ratificados por el Estado Mexicano.

2. Que ha cometido fuera del territorio nacional un delito calificado como grave, antes de su internación al mismo, o

3. Que ha cometido actos contrarios a las finalidades y a los principios de las Naciones Unidas. En el supuesto de la fracción II se deberá atender la naturaleza del delito y que el mismo sea punible conforme a la legislación nacional y a la del país de origen o del país donde se hubiese cometido.

La Secretaría podrá otorgar protección complementaria al extranjero que, no encontrándose dentro de los supuestos del artículo 13 de la Ley, requiera protección para no ser devuelto al territorio de otro país en donde su vida peligre o en donde existan razones fundadas para creer que estaría en peligro de ser sometido a tortura u otros tratos o penas crueles, inhumanos o degradantes. Para el otorgamiento de dicha protección la Secretaría deberá considerar la opinión de la Secretaría de Relaciones Exteriores, misma que se solicitará conforme a lo previsto en el artículo 24 de la Ley. No se otorgará protección complementaria al 
Esta revista forma parte del acervo de la Biblioteca Jurídica Virtual del Instituto de Investigaciones Jurídicas de la UNAM

extranjero respecto del cual existan motivos fundados para considerar que se encuentra en alguno de los supuestos previstos en el artículo 27 de la presente Ley.

Cuando la Secretaría determine que un solicitante no reúne los requisitos para ser reconocido como refugiado, deberá, en cada caso, evaluar si el extranjero requiere protección complementaria.

La evaluación de protección complementaria deberá ser notificada al extranjero en la misma resolución recaída en el procedimiento de reconocimiento de la condición de refugiado. Si la Secretaría determina que un extranjero requiere protección complementaria, expedirá el documento migratorio correspondiente que acredite su situación migratoria regular en el país en los términos de las disposiciones aplicables. En caso contrario, éste quedará sujeto a las disposiciones migratorias correspondientes.

La Secretaría podrá retirar la protección complementaria otorgada solamente en los siguientes casos:

1. En los que se acredite que un extranjero ocultó o falseó la información proporcionada, o

2. Cuando desaparezcan las circunstancias que motivaron el otorgamiento de la protección complementaria.

La Secretaría cesará el reconocimiento de la condición de refugiado al que:

1. Se ha acogido voluntariamente a la protección del país de su nacionalidad.

2. Habiendo perdido su nacionalidad, la recobra voluntariamente.

3. Ha adquirido una nueva nacionalidad y disfruta de la protección del país de su nueva nacionalidad.

4. Se ha establecido voluntariamente en el país que había abandonado o fuera del cual había permanecido de conformidad con el artículo 13 de la Ley.

5. Han desaparecido las circunstancias por las cuales fue reconocido como refugiado y no puede continuar negándose a acogerse a la protección del país de su nacionalidad, o

6. No tiene nacionalidad y por desaparecer las circunstancias en virtud de las cuales fue reconocido como refugiado, está en condiciones de regresar al país donde tenía su residencia habitual. No cesará el reconocimiento de la condición de refugiado en los supuestos comprendidos en las fracciones $\mathrm{V}$ y $\mathrm{VI}$, cuando el refugiado pueda invocar razones graves derivadas de la persecución 


\section{OSCAR CRUZ BARNEY}

por la que originalmente dejó su país de origen, o que mantenga un fundado temor de persecución por alguno de los motivos contemplados en el artículo 13 de la Ley.

La Secretaría revocará el reconocimiento de la condición de refugiado cuando, con posterioridad a su reconocimiento, un refugiado realice conductas contempladas en las fracciones I y III del artículo 27 de la Ley.

La Secretaría cancelará el reconocimiento de la condición de refugiado, cuando tenga en su poder pruebas fehacientes que demuestren que el solicitante ocultó o falseó los hechos declarados sobre los que basó su solicitud de tal forma que, de haberse conocido oportunamente, hubieran ocasionado el no reconocimiento de la condición.

Los refugiados y extranjeros que reciban protección complementaria, podrán solicitar que se suspenda en cualquier momento la condición o protección que reciben, para lo cual será necesario dar aviso a la Secretaría. En caso de que un refugiado o extranjero que reciba protección complementaria abandone el país y solicite el reconocimiento de la condición de refugiado, otorgamiento de una condición similar o la residencia permanente en otro país, la Secretaría procederá a la suspensión de la condición de refugiado misma que podría ser reactivada mediante solicitud y su evaluación en un eventual retorno. En los casos a que se refiere este artículo, la Secretaría realizará las acciones necesarias para dar por terminados los efectos de su condición de estancia en territorio nacional en los términos previstos por el reglamento.

Corresponde a la Secretaría cesar, cancelar o revocar el reconocimiento de la condición de refugiado. Para lo anterior, la Secretaría deberá emitir resolución fundada y motivada con respecto a la cesación, cancelación o revocación del reconocimiento de la condición de refugiado, dentro de los 45 días hábiles contados a partir del día en que se inicie el procedimiento respectivo y la cual deberá ser notificada al extranjero. El plazo para emitir la resolución podrá ampliarse hasta por un período igual a juicio de la Secretaría y únicamente cuando existan razones justificadas que lo motiven, las que serán:

1. La falta de traductor o especialistas que faciliten la comunicación con el refugiado.

2. La imposibilidad de realizar entrevistas en razón de las condiciones de salud del refugiado.

3. La petición del extranjero para aportar elementos, o

4. Cualquier otra circunstancia derivada del caso fortuito o fuerza mayor que imposibilite a la Secretaría el adecuado desarrollo del procedimiento. 
Esta revista forma parte del acervo de la Biblioteca Jurídica Virtual del Instituto de Investigaciones Jurídicas de la UNAM

La resolución deberá ser notificada por escrito al extranjero. La Secretaría al momento de realizar las notificaciones procurará que el extranjero comprenda el sentido de la resolución.

En contra de la resolución procederá el recurso de revisión, mismo que deberá ser presentado dentro de los 15 días hábiles siguientes contados a partir de la notificación respectiva. De igual forma el extranjero podrá interponer los medios de defensa que estime pertinentes de conformidad con las disposiciones aplicables.

El refugiado que se encuentre sujeto a un procedimiento de cesación, revocación o cancelación del reconocimiento de la condición de refugiado, tendrá entre otros, derecho a:

1. Recibir información clara, oportuna y gratuita sobre el procedimiento respectivo y sobre los derechos inherentes al mismo, así como los recursos que esta Ley y otras disposiciones aplicables le conceda.

2. Realizar las manifestaciones que a su derecho convengan y aportar todas las pruebas que considere convenientes, y

3. Contar, en caso de ser necesario, de forma gratuita con el apoyo de un traductor o intérprete de su idioma o uno de su comprensión y de los especialistas que se requieran para facilitar la comunicación, mismos que en todo momento deberán de preservar la confidencialidad de la información.

Al extranjero al que le sea cesado el reconocimiento de la condición de refugiado, no podrá, bajo ninguna circunstancia, realizar nueva solicitud con base en los mismos hechos y argumentos por los que fue reconocido. En los casos que el reconocimiento de la condición de refugiado sea revocado o cancelado, el extranjero no podrá, bajo ninguna circunstancia, realizar nueva solicitud bajo los mismos hechos y argumentos por los que fue reconocido o gozar de la condición derivada.

Conforme al artículo 44 en virtud de las condiciones que presentan los refugiados al salir de su país de origen respecto de los demás extranjeros, deberán recibir las mayores facilidades posibles para el acceso a los derechos y garantías consagradas en la Constitución Política de los Estados Unidos Mexicanos y los instrumentos de derechos humanos debidamente firmados y ratificados por el Estado mexicano, de conformidad con las disposiciones aplicables, entre ellos:

1. Recibir apoyo de las instituciones públicas, en el ejercicio y respeto de sus derechos.

2. Recibir servicios de salud.

3. Recibir educación y, en su caso, el reconocimiento de sus estudios. 
4. Ejercer el derecho al trabajo, pudiéndose dedicar a cualquier actividad, siempre que sea lícita, sin perjuicio de las disposiciones jurídicas que resulten aplicables en la materia.

5. Obtener el documento de identidad y viaje expedido por la Secretaría de Relaciones Exteriores.

6. Solicitar la reunificación familiar, y

7. Obtener el documento migratorio expedido por la Secretaría, que acredite su condición de estancia como residente permanente. Artículo 45. Los extranjeros a los que hace referencia el presente ordenamiento tienen la obligación de respetar la Constitución Política de los Estados Unidos Mexicanos, las leyes y reglamentos, así como las medidas adoptadas para mantener el orden público.

En el caso de los refugiados reconocidos en otro país, la Secretaría podrá autorizar a un extranjero reconocido como refugiado en otro país, que no gozaba de protección efectiva, su internación como refugiado al territorio nacional, de conformidad con lo establecido en el reglamento de la Ley.

A los refugiados y aquellos extranjeros que se les otorgue protección complementaria se les concederá la residencia permanente en los Estados Unidos Mexicanos. Los refugiados y aquellos extranjeros que requieren protección complementaria de conformidad con los tratados internacionales de observancia obligatoria en México y demás ordenamientos aplicables, podrán residir en cualquier lugar de la República Mexicana debiendo informar a la Secretaría sus cambios de residencia, de conformidad con lo establecido en el reglamento. La Secretaría podrá determinar el lugar de residencia de solicitantes, refugiados o extranjeros que requieran o reciban protección complementaria, solamente cuando se emitan lineamientos conforme al artículo 26 de la Ley.

Si hay razones fundadas para considerar que el solicitante, refugiado, o extranjero que reciba protección complementaria, pone en riesgo la seguridad nacional, o bien, si habiendo sido objeto de una condena definitiva por un delito grave cuya naturaleza constituye una amenaza a la sociedad, podrá ser expulsado o devuelto a otro país. En caso de presentarse una solicitud de extradición de un extranjero que hubiese solicitado el reconocimiento de la condición de refugiado o de un refugiado, la Secretaría de Relaciones Exteriores deberá notificar a la Secretaría de Gobernación en un plazo no mayor a cinco días hábiles, a partir de la fecha en que reciba la solicitud de extradición. Para efectos de lo señalado en el párrafo anterior, la Secretaría deberá remitir a la Secretaría de Relaciones Exteriores, el listado de los solicitantes y refugiados de conformidad con el reglamento. En el caso a que se refiere 
Esta revista forma parte del acervo de la Biblioteca Jurídica Virtual del Instituto de Investigaciones Jurídicas de la UNAM

el primer párrafo de este artículo la Secretaría, durante el procedimiento de extradición, deberá emitir su opinión a la Secretaría de Relaciones Exteriores, respecto de si la solicitud de extradición es acorde o no con la salvaguarda del principio de no devolución y, en su caso, las acciones que fuesen procedentes a su juicio, para cumplir con dicho principio. Dicha opinión se hará llegar al juez de conocimiento, por conducto de la Secretaría de Relaciones Exteriores, para su consideración, antes de que emita la opinión jurídica a que se refieren los artículos 28 y 29 de la Ley de Extradición Internacional. Cuando una solicitud de reconocimiento de la condición de refugiado se encuentre pendiente de resolución, la Secretaría deberá resolver sobre el reconocimiento de la condición de refugiado en un plazo no mayor a diez días hábiles, sin perjuicio de lo dispuesto por los artículos 18, 19, 20, 21, 22 y 23 de la ley.

La Secretaría deberá adoptar las medidas necesarias para brindar asistencia institucional a los refugiados, así como auxiliarlos con el objeto de facilitar su integración al país, tomando en consideración el contexto social y cultural de donde provengan, así como si son niñas, niños y adolescentes, personas adultas mayores, con discapacidad, mujeres embarazadas, enfermos crónicos, víctimas de tortura u otros tratos o penas crueles, inhumanos o degradantes, de abuso sexual y violencia de género, de trata de personas o a cualquier otra persona que pudiese encontrarse en estado de vulnerabilidad.

Cuando para el ejercicio de sus derechos y obligaciones el refugiado requiera de los servicios consulares de su país de origen para la obtención de documentos, certificación o acreditación de su estado civil, títulos y demás actos administrativos, las autoridades competentes tomarán las medidas oportunas para apoyar al refugiado, respetando su derecho a no solicitar apoyo de las autoridades del gobierno de su país de origen, incluyendo la posibilidad de no solicitar la apostilla o legalización de documentos de conformidad con las disposiciones aplicables. Para efectos de la reunificación familiar, la Secretaría podrá autorizar, por derivación de la condición de refugiado, la internación a territorio nacional del cónyuge, concubinario, concubina, hijos, parientes consanguíneos hasta el cuarto grado, parientes consanguíneos del cónyuge, concubinario, concubina, hasta el segundo grado que dependan económicamente del refugiado, así como la capacidad económica para su manutención.

En lo que se refiere al asilo político, la Secretaría, sin perjuicio de las obligaciones que les corresponda a otras autoridades y en coordinación con las mismas, adoptará las medidas que estén a su alcance para que los asilados no sean objeto de discriminación motivada por origen étnico 


\section{OSCAR CRUZ BARNEY}

o nacional, género, edad, discapacidad, condición social o económica, condiciones de salud, embarazo, religión, opiniones, preferencias sexuales, estado civil o cualquiera otra que tenga como efecto impedir o anular el reconocimiento o el ejercicio de sus derechos.

Todo extranjero que encuentre en peligro su vida, su libertad o seguridad por ideas o actividades políticas directamente relacionadas con su perfil público, y carezca de la protección de su país, podrá solicitar el otorgamiento de asilo político ante la Secretaría de Relaciones Exteriores, sus delegaciones localizadas fuera del Distrito Federal o la Representación, según corresponda.

La Secretaría de Relaciones Exteriores podrá hacer extensivo, por derivación el otorgamiento de asilo político al cónyuge, concubinario, concubina, sus hijos y los de su cónyuge, concubinario o concubina, que dependan económicamente del asilado, que se encuentren en su país de origen o en territorio nacional con el solicitante, para lo cual deberá considerar la opinión que emita la Secretaría.

El solicitante de asilo político deberá presentarse físicamente en la Representación, en la sede de la Secretaría de Relaciones Exteriores o en sus delegaciones localizadas fuera de la Ciudad de México, a efecto de presentar por escrito su solicitud, y proporcionar sus datos de identificación, los motivos en los cuales fundamenta su solicitud de asilo políti$\mathrm{co}$, así como de todos los elementos que disponga para sustentarla. En el caso en que al solicitante no le sea posible presentar la solicitud por escrito, podrá hacerlo verbalmente. El solicitante de asilo político debe recibir información clara, oportuna y gratuita sobre el procedimiento de otorgamiento de asilo político, así como sobre sus derechos y obligaciones.

Durante el procedimiento, la Secretaría de Relaciones Exteriores o la Representación de considerarlo pertinente, tomará las medidas a su alcance para proveer protección a los solicitantes de asilo político.

La decisión sobre el otorgamiento o no del asilo político será comunicada al solicitante del mismo; el reglamento de esta Ley establecerá el plazo para tales efectos. En los casos en los cuales la Secretaría de Relaciones Exteriores, otorgue asilo político, ésta y la Representación, de manera coordinada, tomarán las medidas necesarias para que, en su caso, el asilado sea trasladado a territorio nacional. Otorgado el asilo político, la Secretaría de Relaciones Exteriores notificará su decisión a la Secretaría a efecto de que esta expida el documento migratorio de conformidad con lo establecido en la Ley de Migración.

En caso de que un extranjero se presente en un lugar destinado en México al tránsito internacional de personas y solicite se le conceda 
Esta revista forma parte del acervo de la Biblioteca Jurídica Virtual del Instituto de Investigaciones Jurídicas de la UNAM

asilo político, la Secretaría determinará si la solicitud corresponde a un posible caso de condición de refugiado o de asilo político. En este último supuesto, informará de inmediato a la Secretaría de Relaciones Exteriores de tal situación, debiendo remitir los datos que lo identifiquen, así como las razones que exponga para sustentar su solicitud.

La Secretaría de Relaciones Exteriores podrá retirar el otorgamiento de asilo político en los siguientes casos:

1. En los que se acredite que el asilado ocultó o falseó la información proporcionada.

2. Por realizar actos en territorio nacional que constituyan un riesgo o amenaza para la seguridad nacional.

3. Cuando existan razones fundadas para considerar que el asilado ha cometido un delito contra la paz, el crimen de genocidio, crímenes de lesa humanidad o crímenes de guerra de los definidos en los tratados internacionales de los que el Estado mexicano sea parte o del delito de terrorismo, o

4. Cuando desaparezcan las circunstancias que motivaron su otorgamiento.

Los asilados podrán renunciar en cualquier momento a la protección que les fue otorgada, para lo cual será necesario dar aviso por escrito a la Secretaría de Relaciones Exteriores, la que comunicará lo conducente a la Secretaría. En caso de que un asilado solicite la protección o residencia permanente en otro país, se entenderá que renuncia a la protección que se le otorgó en los Estados Unidos Mexicanos. En los casos de renuncia a que se refiere el presente artículo, la Secretaría de Relaciones Exteriores realizará las acciones necesarias para dar por terminados los efectos de su condición de estancia en territorio nacional en los términos previstos por el reglamento.

La Secretaría en coordinación con la Secretaría de Relaciones Exteriores, debe adoptar las medidas necesarias para brindar asistencia institucional a los asilados, en los mismos términos que lo establecido en los artículos $54,55,56$ y 57 de la Ley.

\section{CONCLUSIÓN}

Queda mucho trabajo por hacer. México se encuentra ante una oportunidad importante para redefinir las condiciones del trato y atención brindada a los migrantes en su relación con los Estados Unidos de América. La renegociación del TLCAN abre una ventana de oportunidad para ello. 
Esta revista forma parte del acervo de la Biblioteca Jurídica Virtual del Instituto de Investigaciones Jurídicas de la UNAM

Nuestro país debe cumplir con la meta nacional del Plan Nacional de Desarrollo 2013-2018, denominada "México con Responsabilidad Global" y garantizar en el territorio nacional los derechos de las personas migrantes, solicitantes de asilo, refugiadas y beneficiarias de protección complementaria.

El diseño y ejecución de programas de atención especial a grupos vulnerables de migrantes, como niñas, niños y adolescentes, mujeres embarazadas, víctimas de delitos graves, personas con discapacidad y adultos mayores es fundamental.

Deben fortalecerse y hacerse efectivos los procedimientos para el otorgamiento de la condición de refugiado y el otorgamiento en su caso de la protección complementaria.

La garantía de asistencia médica y jurídica debe hacerse efectiva. En el acceso a un efectivo derecho de defensa los colegios de abogados deben jugar un papel preponderante en coordinación con las autoridades estatales. 